\title{
A novel approach for enhancing thermal performance of Battery Modules based on Finite Element Modelling and Predictive modelling mechanism
}

\author{
${ }^{1}$ Akhil Garg,${ }^{1,2}$ C. Ruhatiya, ${ }^{3}$ Xujian Cui, Xiongbin Peng ${ }^{3}$, Yogesh Bhalerao ${ }^{4,5},{ }^{* 1}$ Liang Gao
}

${ }^{1}$ State Key Lab of Digital Manufacturing Equipment \& Technology, School of Mechanical Science and Engineering, Huazhong University of Science and Technology, Wuhan, China ${ }^{2}$ School of Engineering Sciences, Mahindra École Centrale, Hyderabad, Telangana 500043, India ${ }^{3}$ Intelligent Manufacturing Key Laboratory of Ministry of Education, Shantou University, Shantou, China

${ }^{4}$ Department of Mechanical Engineering, MIT Academy of Engineering (MAE), Pune MH 412105, India

${ }^{5}$ Engineering Faculty of Science, University of East Anglia, Norwich Reserch Park, Norwich NR47TJ

\begin{abstract}
Electric Vehicles (EVs) are estimated as the most sustainable solutions for future transportation requirements. However, there are various problems related to the battery pack module and one of such problem is invariable high-temperature differences across the battery pack module due to the discharging and charging of batteries under operating conditions of EVs. Hightemperature differences across the battery module contribute to degradation of maximum charge storage and capacity of Li-ion batteries which ultimately affects the performance of EVs. To address this problem, a Finite Element Modelling (FEM) based Automated Neural Network Search (ANS) approach is proposed. The research methodology constitutes of the four stages: Design of air-cooled battery pack module, setup of the FEM constraints and thermal equations, formulating the predictive model on generated data using ANS and lastly performing multi-objective response optimization of the best fit predictive model to formulate optimum design constraints for the air-cooled battery module. For efficient thermal management of the battery module, an empirical model is formulated using the mentioned methodology for minimizing the maximum temperature differences, standard deviation of temperature across the battery pack module and battery pack volume. The results obtained are as follows: (1) The battery pack module volume is reduced from $0.003279 \mathrm{~m}^{3}$ to $0.002321 \mathrm{~m}^{3}$ by $29.21 \%$, (2) The maximum temperature differences across the eight cells of battery pack module declines from $6.81 \mathrm{~K}$ to $4.38 \mathrm{~K}$ by $35.66 \%$, and (3) The standard deviation of temperature across battery pack decreases from $4.38 \mathrm{~K}$ to $0.93 \mathrm{~K}$ by $78.69 \%$. Thus, the predictive empirical model enhances the thermal management and safety factor of battery module.
\end{abstract}

Keywords: Battery thermal management system; Head conduction; air cooling; thermal efficiency; Energy storage;

*corresponding author email: gaoliang@mail.hust.edu.cn 
The EVs operated on battery packs has become popular due to there less carbon footprints compared to conventional vehicles and is being highly incentivized by major consumer countries around the world [1-2]. The threat of climate change and increasing dependency on fossil fuels in a long term scenario have started a movement in automotive industry to develop sustainable technologies [3]. EVs are also been seen as a new power sources for electric utilities [4-5]. It cannot be said that EVs are 100\% environment friendly, because the electricity needed for charging is still majorly produced from fossil fuels which has large carbon footprints also the metals used in batteries are harmful and rare [6]. However if Well to Wheel (WTW) analysis of EVs and conventional vehicles are compared it can be said that EVs are less polluting if electricity required for charging is generated from renewable energy sources[7]. The lithium-ion batteries (LIBs) are preferred as power source of EVs over other types of batteries, because of power requirements of EVs which can be satisfied by LIBs [8-11]. High energy density and long cycling life make LIBs the preferred option for use in EVs [12-13].

Set of hundreds of Lithium-ion cells are connected in certain pattern to form a battery pack module such that it provides enough power to maintain driving conditions of EVs [13]. These lithium-ion cells of EVs work at a higher value of discharge rate of current producing enormous heat, which gets confined in battery pack module leading to thermal runaway of Energy Storage System(ESS). This results in temperature rise in the battery pack module and accelerated aging of lithium-ion cells in the pack. Due to these reasons, charge acceptance, energy capability, power capability and reliability of batteries are reduced[14]. However, LIBs have high performance at an upper bound temperature of $45^{\circ} \mathrm{C}$ and it is observed battery performance increases as the temperature is increased from room temperature to considerably high temperatures(around $\left.45^{\circ} \mathrm{C}\right)[15]$. Also, very low temperature are found to affect the performance of LIBs, at sub-zero temperature LIBs discharge capacity is reduced due to the 
impedance effect [16] and when charging at high rate while temperature is low, the phenomenon of lithium plating occurs leading to reduced battery life [17]. Its been observed battery pack should have a maximum temperature below $45^{\circ} \mathrm{C}$ and difference in temperatures between cells in battery pack should be below $5^{\circ} \mathrm{C}$ to avoid thermal imbalance for a long working life of a battery $[15,18,19]$. Therefore, a thermal management system is required for battery packs to reduce the heat and maintain an optimum favourable temperature inside a battery pack for better performance of LIBs[19-20].

Battery pack thermal management is mainly classified into three categories. First, is a natural cooling system where the air is the fluid, heat generated by LIBs is exchanged by natural convection process inside the case[21]. Second, is forced cooling system where fluid can be liquid or air, here forced convection occurs inside battery pack when coolant(liquid or air) is introduced in gaps of cells by an external force, such as fan or blower[21-22]. The forced cooling system has better performance than natural cooling system but natural cooling is more economical than forced cooling, there is a trade-off between factors such as weight, power consumption and economical factor[21]. Third is the Phase Change Material (PCM) cooling system, the PCM system can be a good choice because the latent heat related with melting and freezing are capable of storing more heat than sensible thermal storage[23-24]. When Li-ion cells are under working conditions, the PCM will maintain the Li-ion cells at a certain temperature while passively storing the heat. Once the heat generating components (Li-ion cells) are shut-off the PCM will begin to solidify. The PCM based cooling system is efficient in decreasing temperature but there are also challenges for PCMs poor thermal conductivity which decides the thermal transport efficiency, which limits PCMs application where instant response is required to thermal surge [25].

Major studies have been carried out using multi-dimensional numerical analysis and thermal resistance models. Certain design configurations of air-cooled battery pack system are 
numerically modeled and theoretically investigated by Park et al.[26] to get the required thermal specifications. The investigation was conducted on the cooling effect of five different air-flow configuration of a battery system with 36 cells battery pack. It was concluded that the desired cooling performance is attained by using the pressure relief ventilation and tampered manifold without disturbing the design of the existing battery system. Using numerical and analytical modelling the flat-plate battery stacks and cylindrical battery stacks were compared by Xun et al.[27] for getting required air cooling conditions. Two dimensionless parameters, cooling energy efficiency and compactness of battery stacks were varied and, it was concluded that the cylindrical battery stacks were less compact and more efficient under air cooling conditions. Yang et al.[28] concluded that considering design requirement and air cooling conditions, a battery pack in aligned arrangement generates lower temperature compared to a staggered arrangement, but the only drawback is it requires more space comparatively. It is concluded by Wang et al.[29] that when the fan is located on top of the battery pack module, best cooling performance is obtained. Also $5 \times 5$ cubic arrangement is proposed for a battery pack with 24/25 arrangement for Li-ion 18650 cells. This occupies lesser space and better cooling is obtained compared to $1 \times 24$ and $3 \times 8$ arrangements of cells in a battery pack.

Previous work of authors has utilized genetic algorithms, support vector machine, response surface method, and surrogate modeling combined with Computational Fluid Dynamics (CFD) tools to address the issue of temperature optimization of battery packs. Li et al.[30] reported simultaneous system volume and cooling performance optimization using CFD based surrogate modelling and found $34 \%$ decrease of system volume and $51.9 \%$ decrease of maximum temperature differences. Liao et al.[31] presented optimization of temperature differences for better thermal performance of battery pack using Central Composite Design (CCD) and Response Surface Methods (RSM). Yun et al. [32] designed a framework for simultaneous minimization of battery pack volume and temperature differences using Support Vector 
Simulated Annealing (SA). It was found a decrease of $29 \%$ in volume and $42 \%$ in temperature

difference was reported. In brief, these researches focused on the metaheuristics algorithms whose performance is sensitive to choice of settings and often has to be combined with other complex optimization algorithm to optimize it. However, this work illustrates a simpler Finite Element Modelling (FEM) based Automated Neural Network Search (ANS) approach for minimization of temperature related effects and volume of the pack. Settings in ANS approach is selected automatically based on effective search mechanisms.

Current study focused more on optimization of design and configuration of battery pack to reduce volume and maximum temperature differences simultaneously. Considering the working conditions of EVs, temperature differences and distribution are important factor which are difficult to optimize [33-35]. Moreover, considering air cooling factors simultaneous optimization of battery pack volume is important to save space in EVs[36]. However, the past literature's hardly considered all these aspects simultaneously for comprehensive optimization of battery pack module. In this context, a comprehensive FEM based ANS approach is proposed. In this proposed approach, firstly the data generated from Finite Element Analysis (FEA) on battery pack module is fed into ANS architecture for generation of models. The five geometric parameters and volume of battery module are considered for model and the output to design an efficient battery pack air cooling system, which optimizes the system volume and cooling performance simultaneously. This paper is structured as follows. Section 2 presents detailed description of the research problem. Section 3 proposes the comprehensive design optimization methodology along with the numerical model. Section 4 provides with results and 142 discussions. In section 5, conclusion is presented. 


\section{Research problem statement}

144 This section describes the research problem on optimization of operational parameters in air 145 cooling system of battery pack module for obtaining optimal working conditions for EVs 146 shown in Fig.1. A battery pack module containing eight cells is charged and discharged under 147 normal driving conditions as defined in National Renewable Energy Laboratory [37]. Some 148 innovatory ideas were undertaken by assuming the uneven spacing between cells. An uneven gap spacing did not significantly influence the maximum temperature rise of the battery pack module but, it affects the temperature distribution of module. For rigorous investigation, a similar battery module is designed and parameterized, as shown in Fig. 2. The operational parameters are defined as follows:

$\mathrm{X}_{1}$ : Spacing of four cells near the closed end of battery pack module.

$\mathrm{X}_{2}$ : Spacing of four cells near the outlet and inlet for air cooling of battery pack module.

$\mathrm{X}_{3}$ : Spacing in alignment with inlet, between top of the battery cells to the upper board of battery pack module.

$157 \mathrm{X}_{4}$ : Spacing in alignment with outlet, between top of the battery cells to the lower board of 158 battery pack module.

$v$ : Mass flow rate of cooling air in battery pack module.

The aim is to analyse the effects of the mentioned five input design parameters on the cooling performance. Based on optimization and subsequent analysis, the findings shall propose a new design of the battery module with better thermal management and minimum volume. For an efficient air cooling of battery module under normal driving conditions, three objectives are thus defined as follows:

TD: Maximum temperature differences of eight cells (w.r.t the mean temperature). 
TSD: Standard deviation of temperature.

V: Volume of the battery pack module.

Table. 1. Properties of the unit cells used in battery pack model.

\begin{tabular}{|c|c|}
\hline Heat generation rate & $28,000\left(\mathrm{~W} \mathrm{~m}{ }^{-3}\right)(1.3 \times$ US06) \\
\hline Tested drive cycle (aggressive) & $600 \mathrm{sec}$ \\
\hline Power profile & $1.3 \times$ US06 \\
\hline Eight Li-ion cells rating & $15 \mathrm{Ah}$ \\
\hline Ambient temperature & $27^{\circ} \mathrm{C}$ \\
\hline Active area dimensions & $6 \times 145 \times 255 \mathrm{~mm}$ \\
\hline Specific heat capacity & $745 \mathrm{~J} \mathrm{~kg}^{-1} \mathrm{~K}^{-1}$ \\
\hline Thermal conductivity & $27 \mathrm{~W} \mathrm{~m}^{-1} \mathrm{~K}^{-1}$ \\
\hline Density & $2335 \mathrm{~kg} \mathrm{~m}^{-3}$ \\
\hline
\end{tabular}

170

Input parameters

\section{Operating condition}

Battery pack module working conditions in different driving conditions, data collected from market and previous works on battery pack module.

$\begin{array}{ll}\text { minimize } & \mathrm{V} \\ \text { minimize } & \text { TD } \\ \text { minimize } & \text { TSD }\end{array}$

Such that it follows the constraints of equation 4.
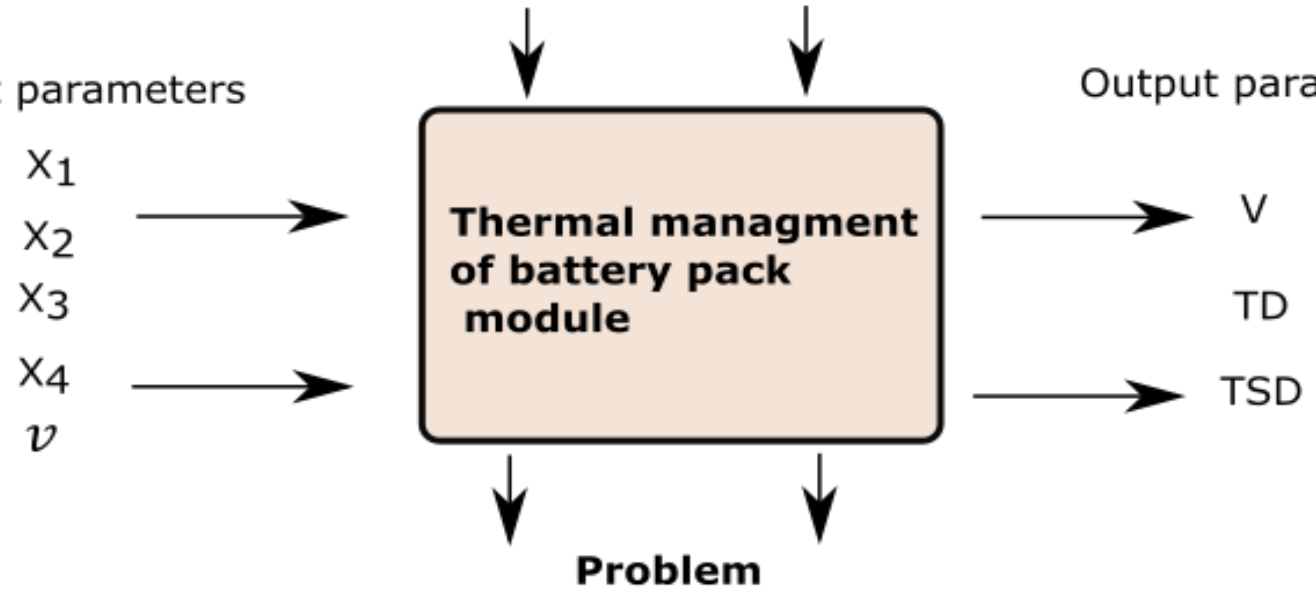

Over-heating of battery pack module, accurate prediction of thermal managment parameters and optimization of design variable of battery pack module for minimizing output variables. 


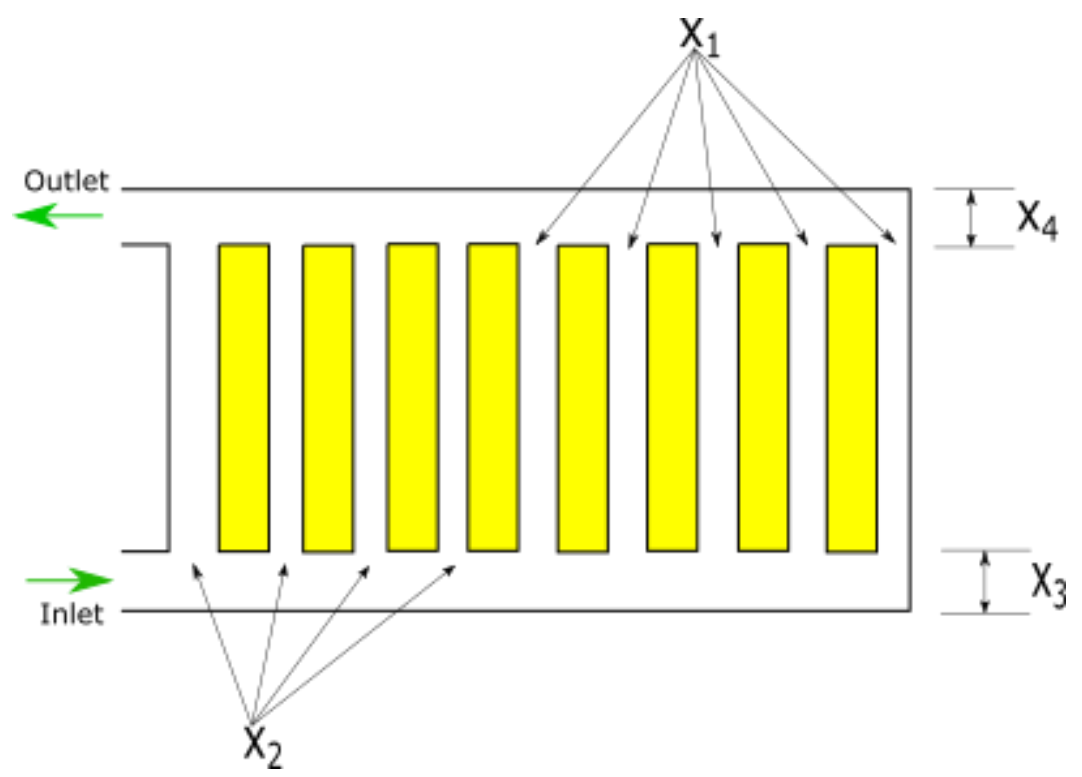

Fig. 2 Schematic diagram of battery module with five design variables

3 Finite Element Modelling based Automated Neural Network Search approach approach is illustrated in two subsections 3.1 and 3.2 as follows. 


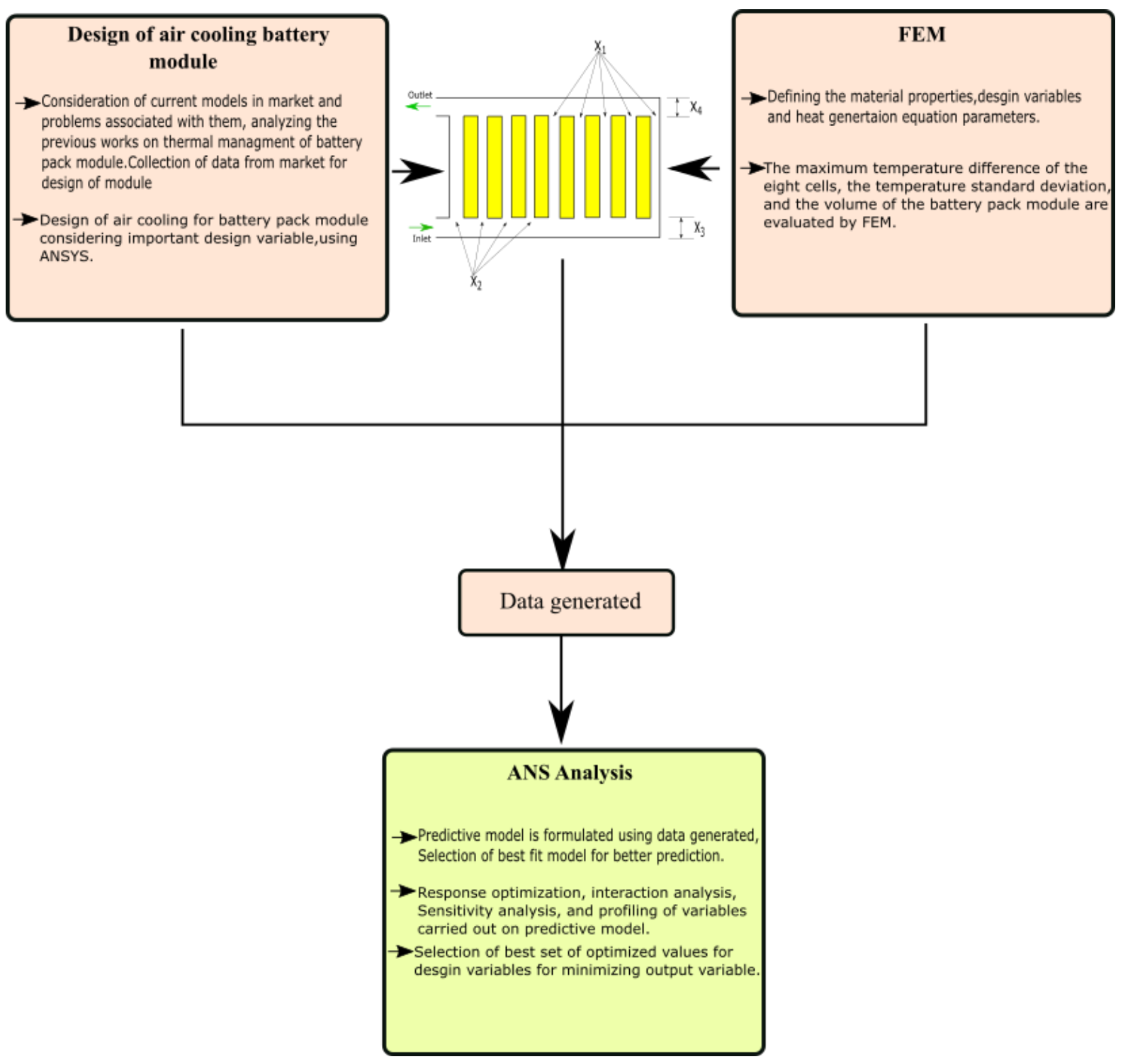

\subsection{Finite Element Method (FEM)}

FEM numerical approach is used for modeling thermal behaviour of battery module in EVs.

These analysis takes the total area of module and divides it into a finite number of subdomains/elements. It also uses variation methods to get the solution of the problem by 

minimizing the error. ANSYS software is used to perform Finite Element Analysis (FEA), it is a widely accepted commercial software package. The knowledge on each of the materials used in the battery module is required for FEM approach to obtain the accurate results.

The FEM was applied on battery pack module (Fig. 4) for thermal management. According to working conditions of battery pack, the heat generation of module is set to value of 28,000 $\mathrm{W} / \mathrm{m}^{3}$, which is 1.3 times normal heat generation conditions [37]. The spatial temperature distribution in each element of the battery pack module is governed by equation 2 ,

$$
\begin{aligned}
& \frac{\partial^{2} T}{\partial x^{2}}+\frac{\partial^{2} T}{\partial y^{2}}+\frac{\partial^{2} T}{\partial z^{2}}+\frac{\dot{q}_{t}}{k}=\frac{1}{\alpha} \frac{\partial T}{\partial t} \\
& \dot{q}_{t}=R_{i} i^{2}-T \Delta S \frac{i}{n F}
\end{aligned}
$$

where, $\mathrm{x}, \mathrm{y}$ and $\mathrm{z}$ are spatial directions, $\mathrm{k}$ is thermal conductivity $(\mathrm{W} \cdot \mathrm{m}-1 \cdot \mathrm{K}-1), \alpha=$ thermal diffusivity $\left(\mathrm{m}^{2} \cdot \mathrm{s}^{-1}\right) \cdot \dot{q}_{t}$ is the rate of the internal heat generation per unit volume, $R_{i}$ is the equivalent resistance of $\mathrm{Li}$-ion cell, $i$ is the discharge current of $\mathrm{Li}$-ion cell per unit volume, $F$ is the Faraday number and $\Delta S$ is the entropy change, parameters for $\dot{q}_{t}$ are referred from equation 3.

The results obtained are verified including considerations of fitness function accuracy and mesh independence for the thermal analysis and optimization algorithm. The study aims to demonstrate the effectiveness of non-gradient based optimization in searching for optimum cell arrangement and reveal design principles that can be applied for battery thermal management.

After constructing the geometry, meshing, heat generation and governing equations are subsequently applied. In APDL, solid geometry are generally meshed automatically with restraints. For this case, the computational meshes are generated in quadrilateral elements with an edge length of $0.2 \mathrm{~cm}$ and maximum aspect ratio of 1.5 for reasonable computing time. As 
the geometry is altering, the number of elements constructed varies from 5,000 to 10,000 .

Meshes in the core are refined by increasing the mesh density to achieve higher accuracy in simulating the thermal response.

Authors have done trial-and-error analysis for investigating mesh influence on performance of model. In order to improve the accuracy in FEM modelling, the number and shape of elements generated are increased and tuned for this particular design. Even the meshes in APDL are created automatically, the size level of elements is further altered to the smallest value by instructing stricter restraints. Ideally, there is not much change in the temperature difference as well as its standard deviation.

The air cooling battery module (Fig. 4) is analyzed in ANSYS by incorporating the basic required information as mentioned in [37-38]. The input parameters $\mathrm{X}_{1}, \mathrm{X}_{2}, \mathrm{X}_{3}, \mathrm{X}_{4}$ and $v$ are varied in battery pack module for the evaluation of maximum temperature difference (TD) of eight cells (w.r.t the mean temperature), Standard deviation of Temperature (TSD) and volume of battery pack module (V). In the present work, the heat generation rate is fixed. All three outputs are dependent on all five input parameters and the input parameters are varied as shown in equation 4. 50 data samples (Table 2) were generated from this process which is then fed into architect of ANS approach for formulation of models for three objective parameters (TD, TSD, V) with respect to the five design variables $\left(X_{1}, X_{2}, X_{3}, X_{4}, v\right)$. The following section discusses about ANS approach.

$$
1 m m \leq x_{1} \leq 4 m m, 1 m m \leq x_{2} \leq 4 m m, 1 m m \leq x_{3} \leq 4 m m, 1 m m \leq x_{4} \leq 4 m m
$$

$$
0.002 \mathrm{Kg} / \mathrm{s} \leq v \leq 0.02 \mathrm{Kg} / \mathrm{s}
$$




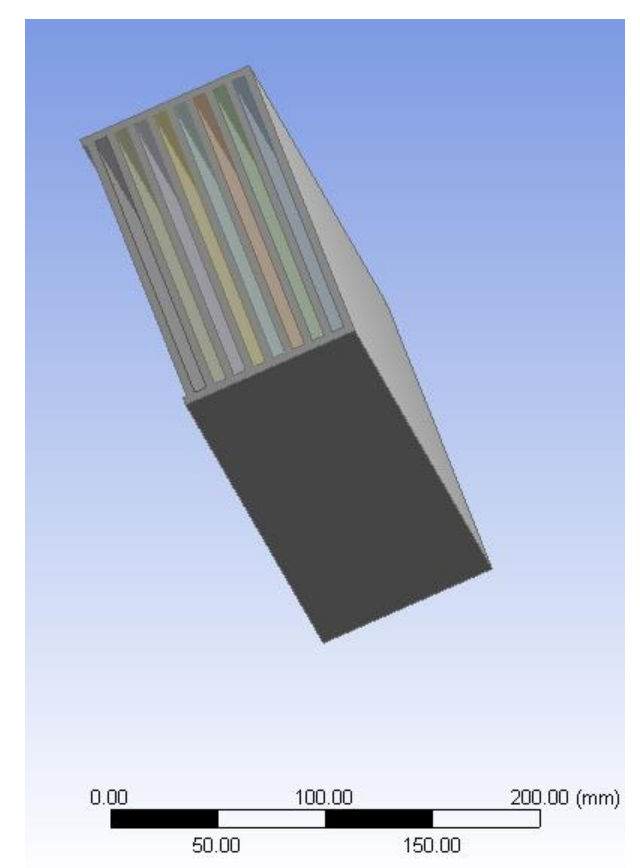

Fig. 4 Computational region of battery module for air cooling.

250 Table 2. Data generated from thermal modelling of battery pack using FEM

\begin{tabular}{|c|c|c|c|c|c|c|c|c|}
\hline & \multicolumn{5}{|c|}{ Input parameters } & \multicolumn{3}{|c|}{ Output parameters } \\
\hline $\begin{array}{c}\text { Run } \\
\text { no. }\end{array}$ & $\mathrm{X} 1(\mathrm{~mm})$ & $\mathrm{X} 2(\mathrm{~mm})$ & $\mathrm{X} 3(\mathrm{~mm})$ & $\mathrm{X} 4(\mathrm{~mm})$ & $\mathrm{v}(\mathrm{kg} / \mathrm{s})$ & V (m3) & $\mathrm{TD}(\mathrm{K})$ & TSD (K) \\
\hline 1 & 2.11 & 1.81 & 3.73 & 1.21 & 0.00974 & 0.002518 & 8.57999 & 4.93789 \\
\hline 2 & 1.39 & 3.55 & 1.45 & 2.89 & 0.01478 & 0.002636 & 5.02078 & 1.11791 \\
\hline 3 & 2.23 & 1.09 & 1.27 & 2.11 & 0.0119 & 0.002405 & 5.09854 & 1.71818 \\
\hline 4 & 1.33 & 2.29 & 2.11 & 1.03 & 0.01262 & 0.002412 & 9.9375 & 5.1425 \\
\hline 5 & 1.93 & 2.65 & 1.33 & 1.87 & 0.0191 & 0.002581 & 4.45999 & 0.954862 \\
\hline 6 & 3.49 & 3.85 & 2.35 & 3.43 & 0.0101 & 0.003112 & 7.56027 & 2.06045 \\
\hline 7 & 1.87 & 2.11 & 3.97 & 3.37 & 0.01442 & 0.002559 & 5.32123 & 2.1044 \\
\hline 8 & 3.61 & 3.31 & 3.49 & 2.77 & 0.00578 & 0.003062 & 9.5433 & 5.13151 \\
\hline 9 & 3.43 & 2.35 & 1.21 & 1.63 & 0.01622 & 0.002812 & 5.95364 & 3.40527 \\
\hline 10 & 2.71 & 3.67 & 3.43 & 2.53 & 0.01802 & 0.002938 & 8.49246 & 4.27937 \\
\hline 11 & 1.45 & 3.25 & 1.39 & 1.57 & 0.00758 & 0.002577 & 7.05188 & 2.90261 \\
\hline 12 & 3.25 & 3.43 & 1.99 & 2.23 & 0.00218 & 0.002969 & 9.9736 & 3.73074 \\
\hline 13 & 1.63 & 3.73 & 3.01 & 3.61 & 0.01082 & 0.002751 & 6.89923 & 2.86642 \\
\hline 14 & 2.89 & 2.77 & 2.05 & 3.85 & 0.00362 & 0.002832 & 8.20624 & 2.39122 \\
\hline 15 & 3.07 & 1.39 & 2.59 & 3.91 & 0.01334 & 0.002665 & 5.30655 & 1.25034 \\
\hline 16 & 1.81 & 3.37 & 3.13 & 3.07 & 0.0029 & 0.002723 & 9.8786 & 4.67427 \\
\hline 17 & 1.51 & 1.45 & 2.17 & 1.69 & 0.00434 & 0.002331 & 8.08087 & 3.81214 \\
\hline 18 & 2.35 & 2.53 & 1.15 & 3.79 & 0.01118 & 0.002674 & 6.44733 & 2.0034 \\
\hline
\end{tabular}




\begin{tabular}{|c|c|c|c|c|c|c|c|c|}
\hline 19 & 2.77 & 1.63 & 3.25 & 2.17 & 0.00254 & 0.002625 & 9.44736 & 4.16184 \\
\hline 20 & 3.31 & 1.51 & 3.91 & 2.35 & 0.01154 & 0.002726 & 7.00259 & 4.73956 \\
\hline 21 & 2.65 & 1.57 & 1.63 & 3.25 & 0.01874 & 0.002583 & 4.67157 & 0.943342 \\
\hline 22 & 3.67 & 2.95 & 1.09 & 2.95 & 0.01226 & 0.002972 & 8.47672 & 2.42016 \\
\hline 23 & 2.29 & 3.91 & 1.51 & 2.83 & 0.00722 & 0.002862 & 6.71506 & 2.24993 \\
\hline 24 & 2.05 & 3.01 & 2.83 & 1.27 & 0.00326 & 0.002675 & 10.5788 & 5.3401 \\
\hline 25 & 2.95 & 3.49 & 1.81 & 2.65 & 0.01982 & 0.002926 & 5.33734 & 0.989422 \\
\hline 26 & 3.37 & 3.07 & 1.75 & 1.15 & 0.00902 & 0.00291 & 8.75858 & 4.42346 \\
\hline 27 & 1.15 & 3.61 & 2.95 & 1.81 & 0.01046 & 0.002607 & 9.96359 & 5.38074 \\
\hline 28 & 3.55 & 2.59 & 3.37 & 1.39 & 0.00686 & 0.002909 & 9.69901 & 5.06779 \\
\hline 29 & 1.69 & 2.47 & 2.47 & 3.97 & 0.01586 & 0.002565 & 4.52307 & 0.975731 \\
\hline 30 & 1.75 & 1.27 & 2.71 & 1.75 & 0.01694 & 0.002359 & 5.04529 & 3.43288 \\
\hline 31 & 3.85 & 1.33 & 2.41 & 2.41 & 0.01514 & 0.002775 & 4.99002 & 1.77981 \\
\hline 32 & 3.79 & 2.71 & 2.53 & 3.49 & 0.01766 & 0.002999 & 5.35361 & 0.823158 \\
\hline 33 & 2.83 & 1.21 & 1.69 & 3.31 & 0.00614 & 0.002565 & 7.46188 & 3.24942 \\
\hline 34 & 2.17 & 1.93 & 3.61 & 3.67 & 0.00506 & 0.002589 & 7.10147 & 2.54214 \\
\hline 35 & 3.73 & 1.75 & 3.19 & 3.55 & 0.0065 & 0.002853 & 6.66385 & 2.38894 \\
\hline 36 & 2.47 & 3.79 & 3.85 & 2.05 & 0.00866 & 0.002909 & 9.95065 & 5.23092 \\
\hline 37 & 2.53 & 3.97 & 2.29 & 1.45 & 0.01406 & 0.002905 & 9.64435 & 4.64936 \\
\hline 38 & 1.57 & 1.03 & 2.77 & 3.13 & 0.00938 & 0.002311 & 5.05328 & 1.41773 \\
\hline 39 & 1.03 & 2.17 & 3.55 & 2.29 & 0.00794 & 0.002381 & 8.4606 & 4.81907 \\
\hline 40 & 2.59 & 1.69 & 3.31 & 2.71 & 0.01946 & 0.002611 & 4.97839 & 3.19006 \\
\hline 41 & 3.01 & 3.13 & 3.67 & 3.73 & 0.01298 & 0.002941 & 6.77084 & 3.98288 \\
\hline 42 & 3.19 & 1.15 & 2.23 & 1.33 & 0.0083 & 0.002599 & 7.51358 & 4.89955 \\
\hline 43 & 2.41 & 2.23 & 1.03 & 1.99 & 0.0047 & 0.002605 & 7.53839 & 2.22204 \\
\hline 44 & 1.99 & 2.83 & 3.79 & 1.51 & 0.01658 & 0.002658 & 8.63937 & 4.70958 \\
\hline 45 & 1.09 & 1.87 & 1.57 & 3.01 & 0.0137 & 0.002326 & 4.16092 & 1.22898 \\
\hline 46 & 1.21 & 2.89 & 2.89 & 2.59 & 0.01838 & 0.00252 & 6.7894 & 3.75226 \\
\hline 47 & 3.13 & 2.05 & 2.65 & 1.09 & 0.0173 & 0.002727 & 9.17682 & 5.27326 \\
\hline 48 & 3.97 & 3.19 & 3.07 & 1.93 & 0.0155 & 0.003086 & 7.11981 & 3.5573 \\
\hline 49 & 3.91 & 1.99 & 1.87 & 2.47 & 0.00542 & 0.002878 & 7.23776 & 2.36477 \\
\hline 50 & 1.27 & 2.41 & 1.93 & 3.19 & 0.00398 & 0.002452 & 8.16791 & 3.25939 \\
\hline
\end{tabular}

\section{$254 \quad 3.2$ Automated Neural Network Search approach}

255 ANS is an machine learning method used for predictive modelling of complex systems. The

256 principle of ANS is same as Artificial Neural Network (ANN), except the activation function

257 and training algorithm selection is automated. The ANS model can optimize its response by 
adjusting it according to the feedback it receives. The network/architecture of such model is shown in Fig. 5. When the network is implemented, the input variable values are placed in the input units, the hidden and output layer units are gradually executed in their serial order

261 triggered by activation functions and trained on the basis of errors. Random weight 262 initialization is preferred option for this particular analysis as the activation function and training algorithm is automated. It is found that generally, the two layer neural network with tan-sigmoid activation/threshold functions at hidden layer and pure linear activation function at output layer can train for any set of non-linear data [39]. Output parameters are affected by a great variety of interaction between input parameters. It is very difficult to illustrate their

267 relationship by the use of conventional methods. Therefore, ANS is preferred tool in this perspective. The ANS facility is used for formulating the neural networks with various configurations and settings while requiring nominal specifications. It forms number of networks models with algorithmic combinations. The network which achieve the highest correlation coefficient value between targets and outputs of the network is chosen. In ANS,

272 there are mainly two types of networks, Multilayer Perceptron (MLP) network type and Radial

273 Basis Function (RBF) network. In present work, we choose MLP as network type because the 274 problem is multi-dimensional and multi-objective in nature [39]. The STATISTICA 12 software package is used to implement this MLP network. 


\section{Input Layer Hidden Layer Output Layer}

276

The data generated from FEM is divided into three different sets comprising of training, testing and validation. The training data is set to $75 \%$, test data to $15 \%$ and validation data to $10 \%$. The sampling of data is done randomly. Networks to train is set to 2000 and 10 best performance coefficient networks are retained. The ANS models are selected on basis of there performance coefficient values (Table 5). The ANS models with high performance coefficient and simultaneously having low error values, are accurate and stable for optimization. The value of seed for sampling is 1000 . After training, we retain 8 networks which are best suited for predictive modelling for 3 outputs. Two models were formulated for 3 output variables. Settings used for $\mathrm{V}\left(\mathrm{m}^{3}\right)$, and TSD $(\mathrm{K})$ is shown in table 3 and settings used for TD (K) is shown in table 4. The networks are trained and tested on FEM generated data for thermal management of battery pack module. Fig. 3 shows the flowchart illustration of methodology undertaken. The main objective for network generation is to formulate a robust and an accurate predictive 
model. Further, optimization of these model results in optimum values of five design variables $\left(\mathrm{X}_{1}, \mathrm{X}_{2}, \mathrm{X}_{3}, \mathrm{X}_{4}, \mathrm{v}\right)$ that simultaneously optimizes the three outputs (TD, TSD, V).

Table 3. Settings of the Automated neural network search for V and TSD outputs.

\begin{tabular}{|c|c|}
\hline Settings & Values \\
\hline Multilayer Perceptron (MLP) & $\begin{array}{c}\text { Min hidden units }=10, \\
\text { Maximum hidden units }=10\end{array}$ \\
\hline Radial Basis Function (RBF) & $\begin{array}{c}\text { Min hidden units }=0, \\
\text { Maximum hidden units }=0\end{array}$ \\
\hline Networks to train & 2000 \\
\hline Networks to retain & 10 \\
\hline $\begin{array}{c}\text { Type of activation functions used for } \\
\text { hidden and output neurons }\end{array}$ & Identity, logistic \\
\hline
\end{tabular}

Table 4. Settings of the Automated neural network search for TD output.

\begin{tabular}{|c|c|}
\hline Settings & Values \\
\hline Multilayer Perceptron (MLP) & $\begin{array}{c}\text { Min hidden units }=4, \\
\text { Maximum hidden units }=4\end{array}$ \\
\hline Radial Basis Function (RBF) & $\begin{array}{c}\text { Min hidden units }=0, \\
\text { Maximum hidden units }=0\end{array}$ \\
\hline Networks to train & 2000 \\
\hline Networks to retain & 10 \\
\hline $\begin{array}{c}\text { Type of activation functions used for } \\
\text { hidden and output neurons }\end{array}$ & Identity, logistic, Tanh, Exponential, Sine \\
\hline
\end{tabular}

\section{Results and Discussion}

\subsection{Statistical fit of Automated Neural Network Search models}

Table 5 shows the 50 runs for the network generated, the performance (correlation coefficient) of the given networks on the training, testing, and validation data, training algorithm and the activation function for the hidden and output neurons. Only the fewer ANS models (highlighted in Table 5) with the training correlation coefficient higher than 0.955 are chosen as the best networks (Table 6). The model chosen for analysis are model no. 23 and 47 (highlighted red in 
308 Table 6), where model no. 23 (MLP 5-10-3) is used for analysis of V and TSD, and model no.

30947 (MLP 5-4-1) is used for analysis of TD. Fig. 6 describes the fitting of models for all output

310 parameters. The coefficient of determination values are found to be $0.99,0.94$ and 0.86 for $\mathrm{V}$,

311 TD and TSD respectively. Fig. 6 (a), (b) and (c) illustrates line fit plot for three outputs V, TD

312 and TSD respectively. Fig. 7, explains that the input parameters $X_{4}$ and $X_{3}$ are the most

313 dominant ones for influencing outputs (V and TSD) for model no.23, whereas for model no.

$31447, \mathrm{X}_{4}$ and $\mathrm{v}$ are the most dominant input parameters for influencing (TD). Overall, the main

315 influencing input parameters are $\mathrm{X}_{4}, \mathrm{v}$ and $\mathrm{X}_{3}$ for three response variables $\mathrm{V}$, TD and TSD.

Table 5. 50 generated models of Automated Neural Network Search

\begin{tabular}{|c|c|c|c|c|c|c|c|}
\hline Index & $\begin{array}{l}\text { Network } \\
\text { name }\end{array}$ & $\begin{array}{l}\text { Training } \\
\text { Perf. }\end{array}$ & $\begin{array}{l}\text { Test } \\
\text { Perf. }\end{array}$ & $\begin{array}{l}\text { Validation } \\
\text { Perf. }\end{array}$ & $\begin{array}{l}\text { Training } \\
\text { algorithm }\end{array}$ & $\begin{array}{l}\text { Hidden } \\
\text { activation }\end{array}$ & $\begin{array}{l}\text { Output } \\
\text { activation }\end{array}$ \\
\hline 1 & $\begin{array}{l}\text { MLP 5- } \\
8-3\end{array}$ & 0.950015 & 0.884071 & 0.990848 & BFGS 38 & Logistic & Identity \\
\hline 2 & $\begin{array}{l}\text { MLP 5- } \\
8-3\end{array}$ & 0.947831 & 0.881299 & 0.990640 & BFGS 31 & Logistic & Identity \\
\hline 3 & $\begin{array}{l}\text { MLP 5- } \\
8-3\end{array}$ & 0.948579 & 0.881561 & 0.993897 & BFGS 29 & Logistic & Identity \\
\hline 4 & $\begin{array}{l}\text { MLP 5- } \\
8-3\end{array}$ & 0.953264 & 0.883503 & 0.997169 & BFGS 36 & Logistic & Identity \\
\hline 5 & $\begin{array}{l}\text { MLP 5- } \\
8-3\end{array}$ & 0.948555 & 0.852924 & 0.990801 & BFGS 25 & Logistic & Identity \\
\hline 6 & $\begin{array}{l}\text { MLP 5- } \\
8-3\end{array}$ & 0.949140 & 0.887160 & 0.990776 & BFGS 37 & Logistic & Identity \\
\hline 7 & $\begin{array}{l}\text { MLP 5- } \\
8-3\end{array}$ & 0.949538 & 0.880357 & 0.992928 & BFGS 29 & Logistic & Identity \\
\hline 8 & $\begin{array}{l}\text { MLP 5- } \\
8-3\end{array}$ & 0.949767 & 0.870302 & 0.992069 & BFGS 33 & Logistic & Identity \\
\hline 9 & $\begin{array}{l}\text { MLP 5- } \\
8-3\end{array}$ & 0.948773 & 0.876464 & 0.991214 & BFGS 30 & Logistic & Identity \\
\hline 10 & $\begin{array}{l}\text { MLP 5- } \\
\text { 8-3 }\end{array}$ & 0.956261 & 0.872637 & 0.992882 & BFGS 40 & Logistic & Identity \\
\hline 11 & $\begin{array}{l}\text { MLP 5- } \\
9-3\end{array}$ & 0.950602 & 0.898850 & 0.991570 & BFGS 27 & Logistic & Identity \\
\hline 12 & $\begin{array}{l}\text { MLP 5- } \\
9-3\end{array}$ & 0.954556 & 0.887046 & 0.991808 & BFGS 37 & Logistic & Identity \\
\hline 13 & $\begin{array}{l}\text { MLP 5- } \\
9-3\end{array}$ & 0.952105 & 0.876715 & 0.994322 & BFGS 36 & Logistic & Identity \\
\hline 14 & $\begin{array}{l}\text { MLP 5- } \\
9-3\end{array}$ & 0.953413 & 0.880951 & 0.991649 & BFGS 33 & Logistic & Identity \\
\hline 15 & $\begin{array}{l}\text { MLP 5- } \\
9-3\end{array}$ & 0.952844 & 0.885069 & 0.993374 & BFGS 39 & Logistic & Identity \\
\hline 16 & $\begin{array}{l}\text { MLP 5- } \\
9-3\end{array}$ & 0.951527 & 0.891649 & 0.992997 & BFGS 40 & Logistic & Identity \\
\hline 17 & $\begin{array}{l}\text { MLP 5- } \\
9-3\end{array}$ & 0.950306 & 0.873274 & 0.992540 & BFGS 35 & Logistic & Identity \\
\hline
\end{tabular}




\begin{tabular}{|c|c|c|c|c|c|c|c|}
\hline 18 & $\begin{array}{l}\text { MLP 5- } \\
9-3\end{array}$ & 0.951601 & 0.864137 & 0.991732 & BFGS 36 & Logistic & Identity \\
\hline 19 & $\begin{array}{l}\text { MLP 5- } \\
9-3\end{array}$ & 0.947856 & 0.885238 & 0.991718 & BFGS 35 & Logistic & Identity \\
\hline 20 & $\begin{array}{l}\text { MLP 5- } \\
9-3\end{array}$ & 0.952937 & 0.880276 & 0.994892 & BFGS 42 & Logistic & Identity \\
\hline 21 & $\begin{array}{l}\text { MLP 5- } \\
10-3\end{array}$ & 0.948406 & 0.858631 & 0.991307 & BFGS 27 & Logistic & Identity \\
\hline 22 & $\begin{array}{l}\text { MLP 5- } \\
10-3\end{array}$ & 0.951390 & 0.881621 & 0.990769 & BFGS 33 & Logistic & Identity \\
\hline 23 & $\begin{array}{l}\text { MLP 5- } \\
10-3\end{array}$ & 0.968015 & 0.872972 & 0.992018 & BFGS 43 & Logistic & Identity \\
\hline 24 & $\begin{array}{l}\text { MLP 5- } \\
10-3\end{array}$ & 0.949296 & 0.877779 & 0.991130 & BFGS 26 & Logistic & Identity \\
\hline 25 & $\begin{array}{l}\text { MLP 5- } \\
\mathbf{1 0 - 3}\end{array}$ & 0.955552 & 0.863405 & 0.992462 & BFGS 37 & Logistic & Identity \\
\hline 26 & $\begin{array}{l}\text { MLP 5- } \\
10-3\end{array}$ & 0.947882 & 0.893928 & 0.991056 & BFGS 27 & Logistic & Identity \\
\hline 27 & $\begin{array}{l}\text { MLP 5- } \\
10-3\end{array}$ & 0.954687 & 0.867890 & 0.992050 & BFGS 23 & Logistic & Identity \\
\hline 28 & $\begin{array}{l}\text { MLP 5- } \\
10-3\end{array}$ & 0.947397 & 0.871344 & 0.992350 & BFGS 25 & Logistic & Identity \\
\hline 29 & $\begin{array}{l}\text { MLP 5- } \\
10-3\end{array}$ & 0.951077 & 0.867050 & 0.993351 & BFGS 33 & Logistic & Identity \\
\hline 30 & $\begin{array}{l}\text { MLP 5- } \\
10-3\end{array}$ & 0.949470 & 0.874669 & 0.990985 & BFGS 26 & Logistic & Identity \\
\hline 31 & $\begin{array}{l}\text { MLP 5- } \\
7-1\end{array}$ & 0.882770 & 0.775362 & 0.923379 & BFGS 3 & Identity & Logistic \\
\hline 32 & $\begin{array}{l}\text { MLP 5- } \\
7-1\end{array}$ & 0.954002 & 0.918905 & 0.924436 & BFGS 19 & Logistic & Exponential \\
\hline 33 & $\begin{array}{l}\text { MLP 5- } \\
11-1\end{array}$ & 0.848846 & 0.832199 & 0.925970 & BFGS 4 & Identity & Tanh \\
\hline 34 & $\begin{array}{l}\text { MLP 5- } \\
4-1\end{array}$ & 0.963519 & 0.906612 & 0.965862 & BFGS 39 & Logistic & Tanh \\
\hline 35 & $\begin{array}{l}\text { MLP 5- } \\
10-1\end{array}$ & 0.894180 & 0.752153 & 0.935306 & BFGS 9 & Tanh & Exponential \\
\hline 36 & $\begin{array}{l}\text { MLP 5- } \\
4-1\end{array}$ & 0.943157 & 0.893595 & 0.994154 & BFGS 24 & Logistic & Tanh \\
\hline 37 & $\begin{array}{l}\text { MLP 5- } \\
4-1\end{array}$ & 0.925115 & 0.795487 & 0.989075 & BFGS 18 & Exponential & Identity \\
\hline 38 & $\begin{array}{l}\text { MLP 5- } \\
4-1\end{array}$ & 0.945285 & 0.804359 & 0.988869 & BFGS 24 & Logistic & Logistic \\
\hline 39 & $\begin{array}{l}\text { MLP 5- } \\
4-1\end{array}$ & 0.969057 & 0.921703 & 0.994828 & BFGS 41 & Logistic & Identity \\
\hline 40 & $\begin{array}{l}\text { MLP 5- } \\
4-1\end{array}$ & 0.971912 & 0.891941 & 0.992240 & BFGS 31 & Tanh & Logistic \\
\hline 41 & $\begin{array}{l}\text { MLP 5- } \\
4-1\end{array}$ & 0.951497 & 0.828912 & 0.994789 & BFGS 25 & Logistic & Identity \\
\hline 42 & $\begin{array}{l}\text { MLP 5- } \\
4-1\end{array}$ & 0.935016 & 0.817722 & 0.991961 & BFGS 23 & Logistic & Identity \\
\hline 43 & $\begin{array}{l}\text { MLP 5- } \\
4-1\end{array}$ & 0.939505 & 0.850236 & 0.990311 & BFGS 22 & Logistic & Identity \\
\hline 44 & $\begin{array}{l}\text { MLP 5- } \\
4-1\end{array}$ & 0.937383 & 0.792258 & 0.991671 & BFGS 20 & Logistic & Identity \\
\hline 45 & $\begin{array}{l}\text { MLP 5- } \\
4-1\end{array}$ & 0.931978 & 0.835205 & 0.988943 & BFGS 24 & Logistic & Identity \\
\hline 46 & $\begin{array}{l}\text { MLP 5- } \\
4-1\end{array}$ & 0.933245 & 0.761554 & 0.997105 & BFGS 19 & Logistic & Identity \\
\hline
\end{tabular}




\begin{tabular}{|l|l|l|l|l|l|l|l|}
\hline 47 & $\begin{array}{l}\text { MLP 5- } \\
\text { 4-1 }\end{array}$ & $\mathbf{0 . 9 8 5 3 1 8}$ & $\mathbf{0 . 8 3 3 8 8 0}$ & $\mathbf{0 . 9 9 3 0 4 7}$ & BFGS 26 & Tanh & Exponential \\
\hline 48 & $\begin{array}{l}\text { MLP 5- } \\
\text { 5-1 }\end{array}$ & $\mathbf{0 . 9 7 5 1 1 4}$ & $\mathbf{0 . 8 1 9 7 1 2}$ & $\mathbf{0 . 9 9 7 8 4 4}$ & BFGS 23 & Tanh & Exponential \\
\hline 49 & $\begin{array}{l}\text { MLP 5- } \\
\text { 4-1 }\end{array}$ & $\mathbf{0 . 9 6 2 7 1 3}$ & $\mathbf{0 . 8 5 3 7 2 0}$ & $\mathbf{0 . 9 9 8 9 0 0}$ & BFGS 16 & Logistic & Tanh \\
\hline $\begin{array}{l}\text { MLP 5- } \\
\text { 5-1 }\end{array}$ & $\mathbf{0 . 9 7 0 9 3 0}$ & $\mathbf{0 . 9 2 3 7 0 6}$ & $\mathbf{0 . 9 9 5 4 4 4}$ & BFGS 33 & Tanh & Logistic \\
\hline
\end{tabular}

Table 6. Best fit ANS models networks

\begin{tabular}{|l|l|l|l|l|l|l|l|}
\hline Index & $\begin{array}{l}\text { Network } \\
\text { name }\end{array}$ & $\begin{array}{l}\text { Training } \\
\text { Perf. }\end{array}$ & $\begin{array}{l}\text { Test } \\
\text { Perf. }\end{array}$ & $\begin{array}{l}\text { Validation } \\
\text { Perf. }\end{array}$ & $\begin{array}{l}\text { Training } \\
\text { algorithm }\end{array}$ & $\begin{array}{l}\text { Hidden } \\
\text { activation }\end{array}$ & $\begin{array}{l}\text { Output } \\
\text { activation }\end{array}$ \\
\hline 10 & $\begin{array}{l}\text { MLP 5- } \\
8-3\end{array}$ & 0.956261 & 0.872637 & 0.992882 & BFGS 40 & Logistic & Identity \\
\hline $\mathbf{2 3}$ & $\begin{array}{l}\text { MLP 5- } \\
\mathbf{1 0 - 3}\end{array}$ & $\mathbf{0 . 9 6 8 0 1 5}$ & $\mathbf{0 . 8 7 2 9 7 2}$ & $\mathbf{0 . 9 9 2 0 1 8}$ & BFGS 43 & Logistic & Identity \\
\hline 25 & $\begin{array}{l}\text { MLP 5- } \\
10-3\end{array}$ & 0.955552 & 0.863405 & 0.992462 & BFGS 37 & Logistic & Identity \\
\hline 27 & $\begin{array}{l}\text { MLP 5- } \\
10-3\end{array}$ & 0.954687 & 0.867890 & 0.992050 & BFGS 23 & Logistic & Identity \\
\hline $\mathbf{4 7}$ & $\begin{array}{l}\text { MLP 5- } \\
\mathbf{4 - 1}\end{array}$ & $\mathbf{0 . 9 8 5 3 1 8}$ & $\mathbf{0 . 8 3 3 8 8 0}$ & $\mathbf{0 . 9 9 3 0 4 7}$ & BFGS 26 & Tanh & Exponential \\
\hline 48 & $\begin{array}{l}\text { MLP 5- } \\
5-1\end{array}$ & 0.975114 & 0.819712 & 0.997844 & BFGS 23 & Tanh & Exponential \\
\hline 49 & $\begin{array}{l}\text { MLP 5- } \\
4-1\end{array}$ & 0.962713 & 0.853720 & 0.998900 & BFGS 16 & Logistic & Tanh \\
\hline 50 & $\begin{array}{l}\text { MLP 5- } \\
5-1\end{array}$ & 0.970930 & 0.923706 & 0.995444 & BFGS 33 & Tanh & Logistic \\
\hline
\end{tabular}

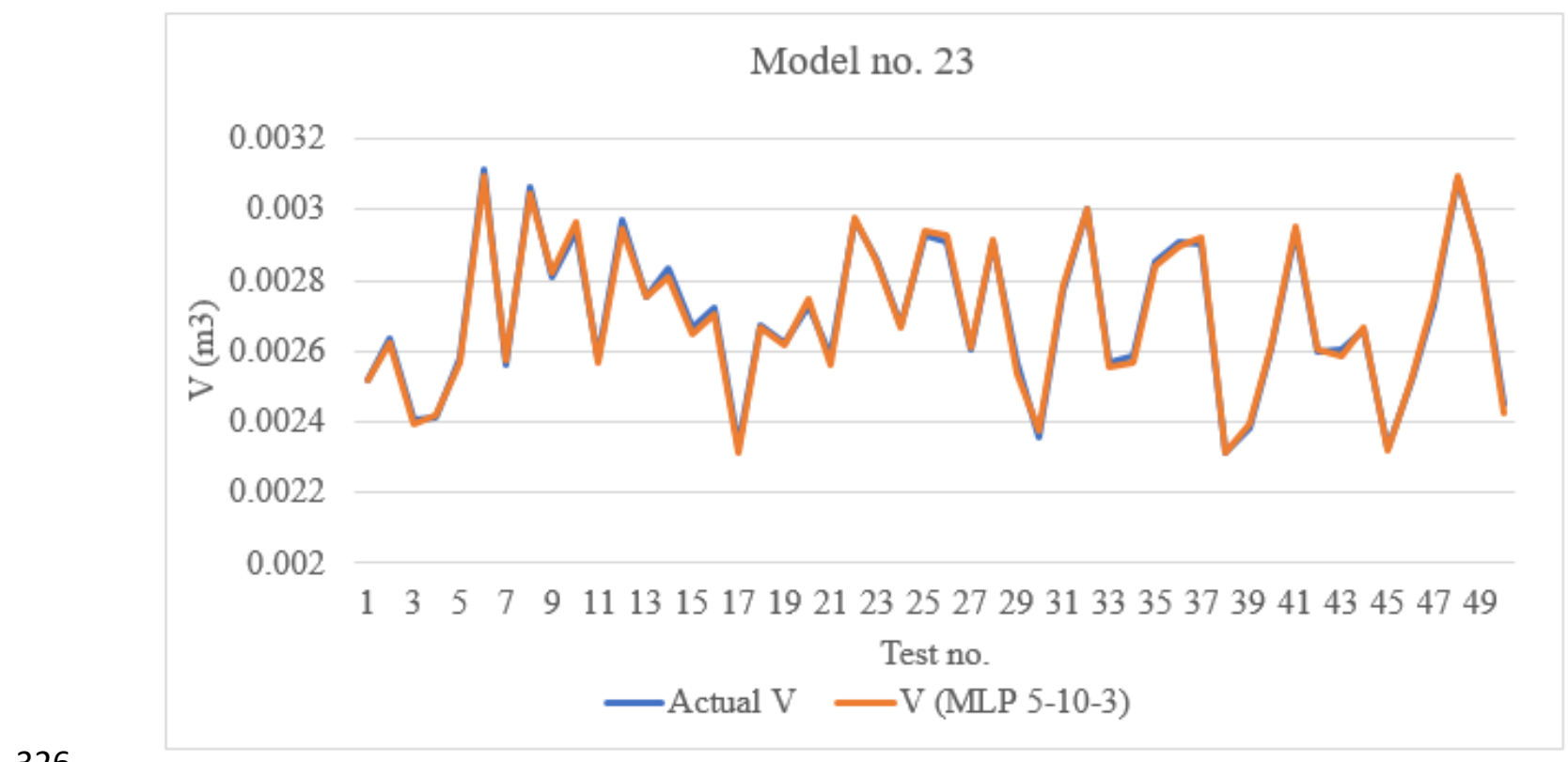


Model no. 23

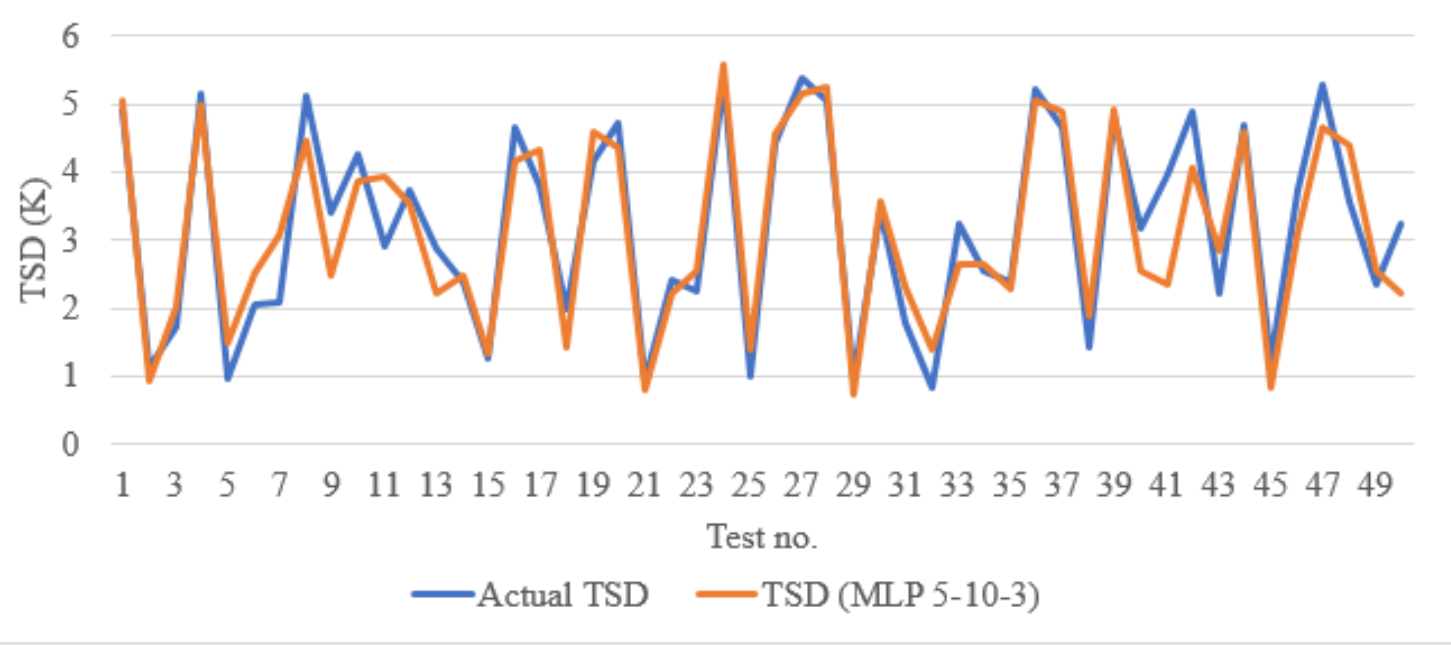

(b)

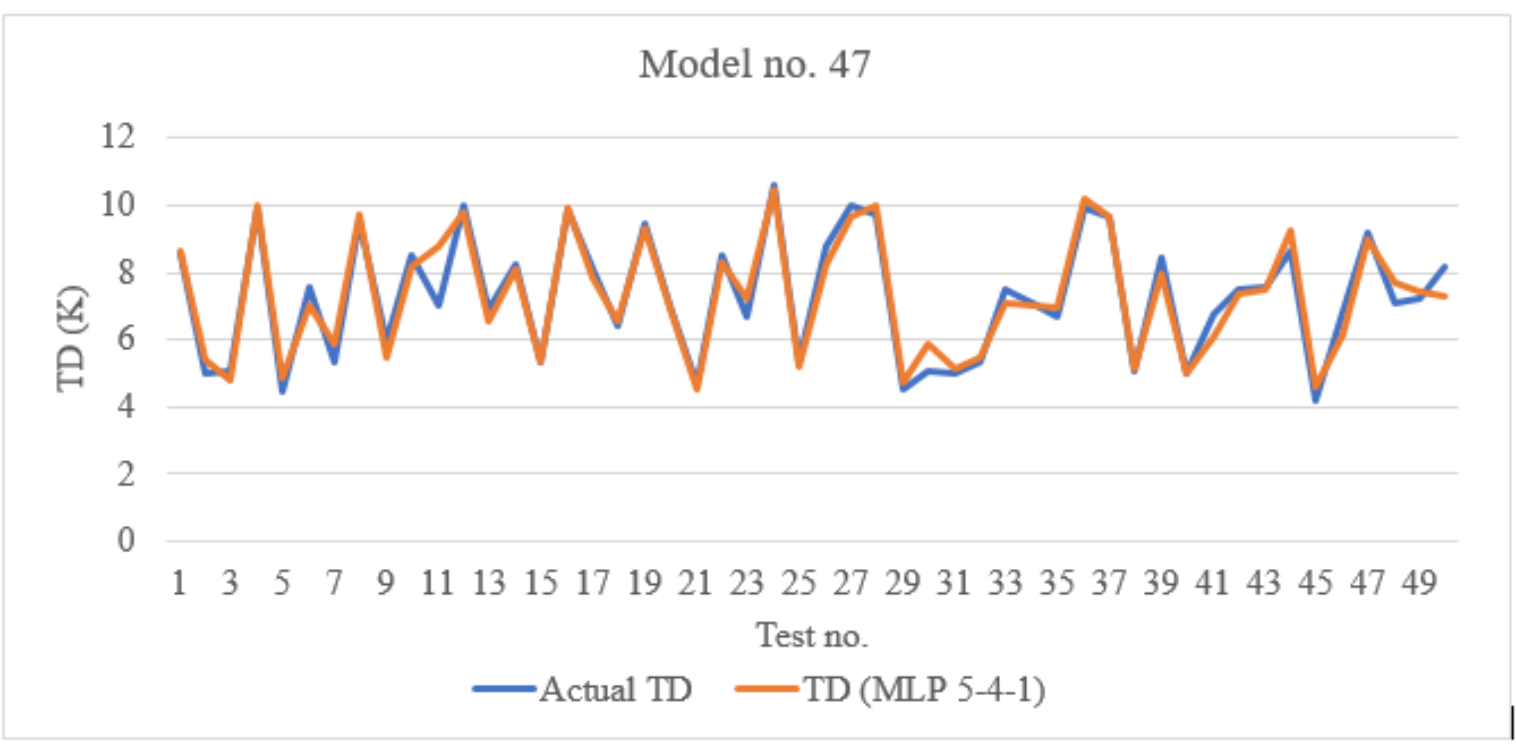

(c) 


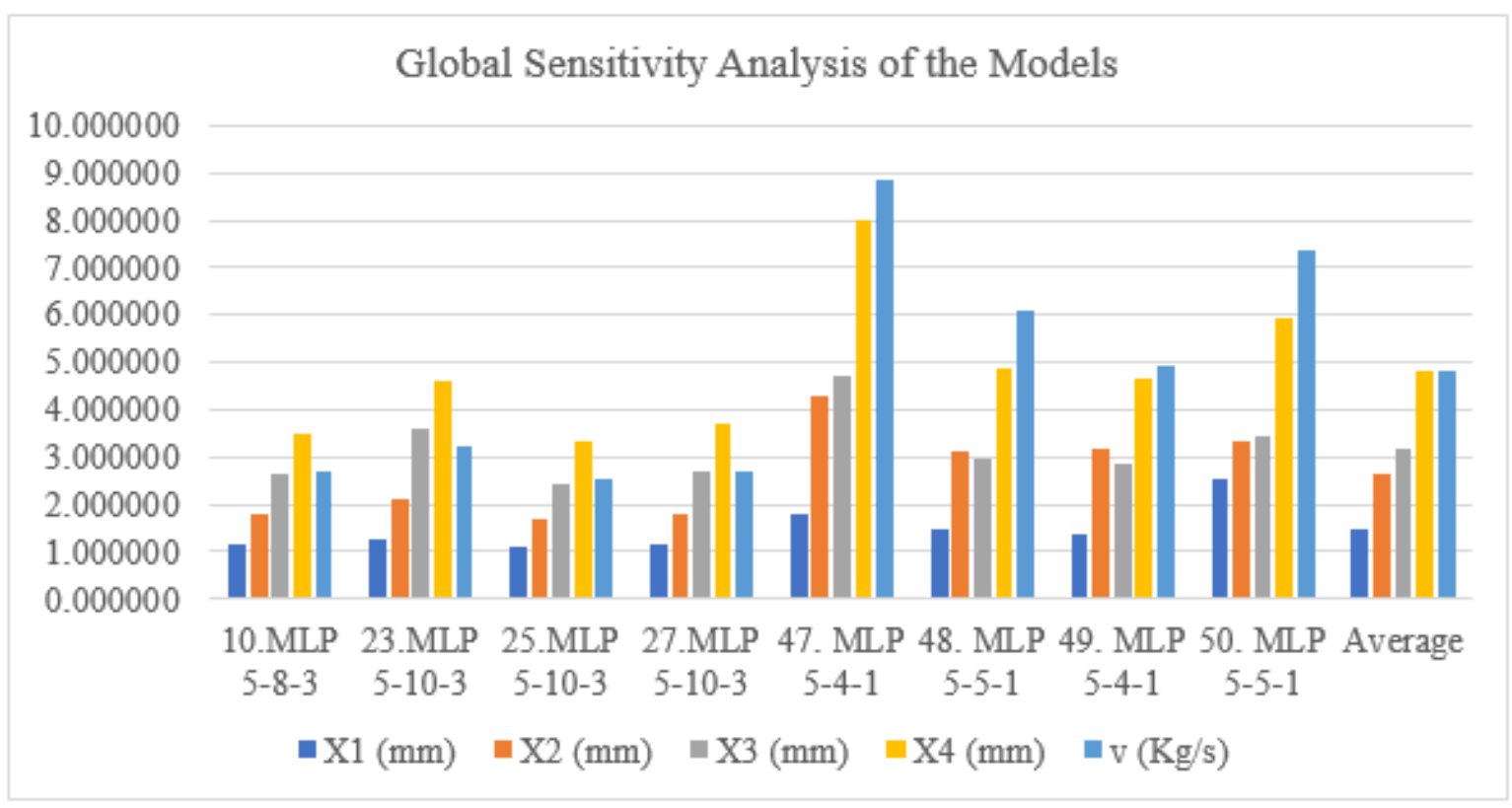

Fig. 7 Global sensitivity analysis for the selected models showing the importance of individual input parameters on the three outputs

\subsection{Response optimization of selected Automated Neural Network Search models}

Response optimization is performed on selected ANS models 23 and 47 for simultaneously minimizing volume of battery module, Temperature difference and Temperature standard deviation. Non-dominated sorting genetic algorithm II (NSGA II ANSYS software package) combined with simplex and grid search is used for optimization. Number of iterations was set to 1000 and number of initial samples was set to 100 . The selected models were evaluated to obtain the minimum volume of battery module, Temperature difference and standard deviation of temperature. The initial values of gap spacing $X_{1}, X_{2}, X_{3}$, and $X_{4}$ are set to $4 \mathrm{~mm}$ and $v$ is set to $0.012 \mathrm{~kg} / \mathrm{s}$. The value of $\mathrm{v}$ is fixed, it is not varied only the values of geometric parameters are varied. Step size is set to 0.0874 and 0.00052 for $\left(\mathrm{X}_{1}, \mathrm{X}_{2}, \mathrm{X}_{3}, \mathrm{X}_{4}\right)$ and $\mathrm{v}$ respectively, and the operating range of design variables were set from $1 \mathrm{~mm}$ to $4 \mathrm{~mm}$ and $0.002 \mathrm{Kg} / \mathrm{s}$ to $0.02 \mathrm{Kg} / \mathrm{s}$ for $\left(\mathrm{X}_{1}, \mathrm{X}_{2}, \mathrm{X}_{3}, \mathrm{X}_{4}\right)$ and $\mathrm{v}$ respectively. Given these set of input values, the initial values 
obtained from ANS models for V, TD and TSD are $0.003279 \mathrm{~m}^{3}, 6.813 \mathrm{~K}$ and $4.37 \mathrm{~K}$ respectively. The multi-objective optimized result is given in Table 7 . The volume of the battery pack module reduces from $0.0033 \mathrm{~m}^{3}$ to $0.0023 \mathrm{~m}^{3}$ by $29.21 \%$, the maximum temperature difference of the eight cells reduces from $6.81 \mathrm{~K}$ to $4.38 \mathrm{~K}$ by $35.66 \%$, and the standard deviation of temperature reduces from $4.38 \mathrm{~K}$ to $0.93 \mathrm{~K}$ by $78.69 \%$. Fig. 8 shows the iterations graph of simplex search for optimization of three response variables. The optimization objective is met w.r.t above optimization constraints and the results obtained on improvement are feasible. The decrease in the volume of battery module after optimization decreases the cost of manufacturing of battery pack. The reduction of TSD by $78.69 \%$ enables the uniformity of temperature in different parts of battery module. Due to reduction of maximum temperature differences by $35.66 \%$ the battery life is maintained in long run and working conditions.

Table 7. Multi-objective optimization results for the battery module

\begin{tabular}{|c|c|c|c|c|c|c|c|c|}
\hline & \multicolumn{5}{|c|}{ Design variables } & \multicolumn{3}{c|}{ Objective variables } \\
\hline & $\mathrm{X} 1(\mathrm{~mm})$ & $\mathrm{X} 2(\mathrm{~mm})$ & $\mathrm{X} 3(\mathrm{~mm})$ & $\mathrm{X} 4(\mathrm{~mm})$ & $\mathrm{v}(\mathrm{Kg} / \mathrm{s})$ & $\mathrm{V}(\mathrm{m} 3)$ & $\mathrm{TD}(\mathrm{K})$ & $\mathrm{TSD}(\mathrm{K})$ \\
\hline Initial values & 4 & 4 & 4 & 4 & 0.012 & 0.003279 & 6.813343 & 4.379044 \\
\hline $\begin{array}{c}\text { Range/ } \\
\text { constraint }\end{array}$ & {$[1,4]$} & {$[1,4]$} & {$[1,4]$} & {$[1,4]$} & $\begin{array}{c}{[0.002,} \\
0.02]\end{array}$ & $\begin{array}{c}\text { minimize } \\
\text { minimize }\end{array}$ & minimize \\
\hline $\begin{array}{c}\text { Optimum values } \\
\text { \% Improvement } \\
\text { in Objective }\end{array}$ & 1.422795 & 1.418067 & 1.698304 & 2.894863 & 0.019353 & 0.002321 & 4.383997 & 0.933274 \\
\hline
\end{tabular}


371

372

373

374

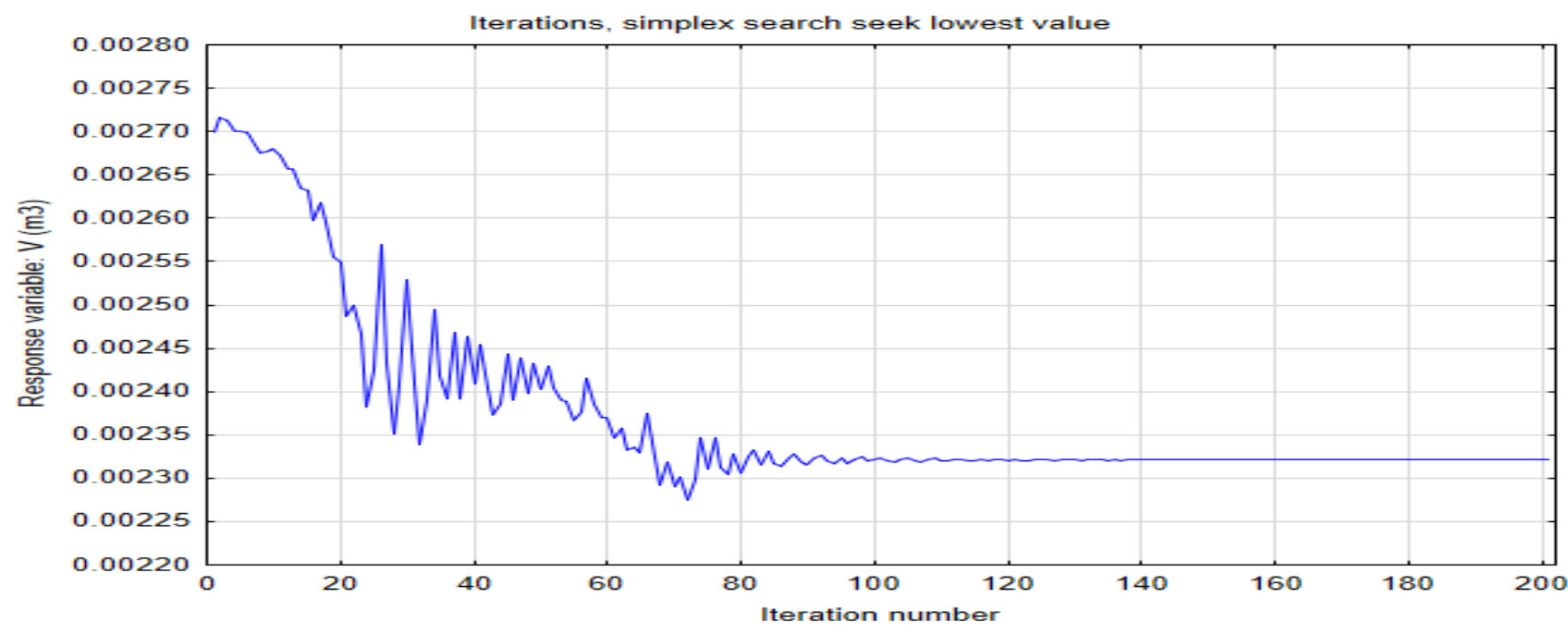

(a.)

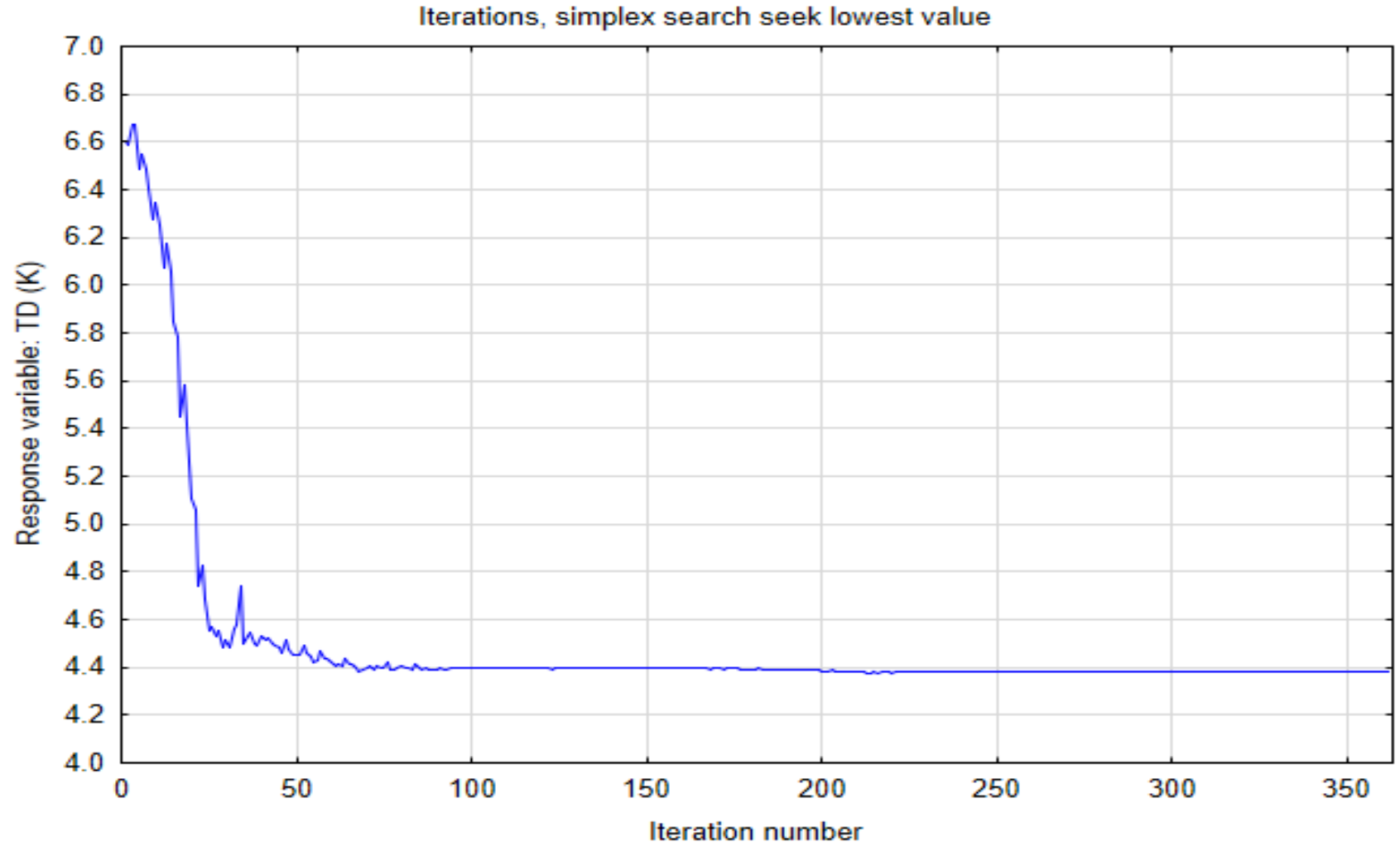

(b.) 


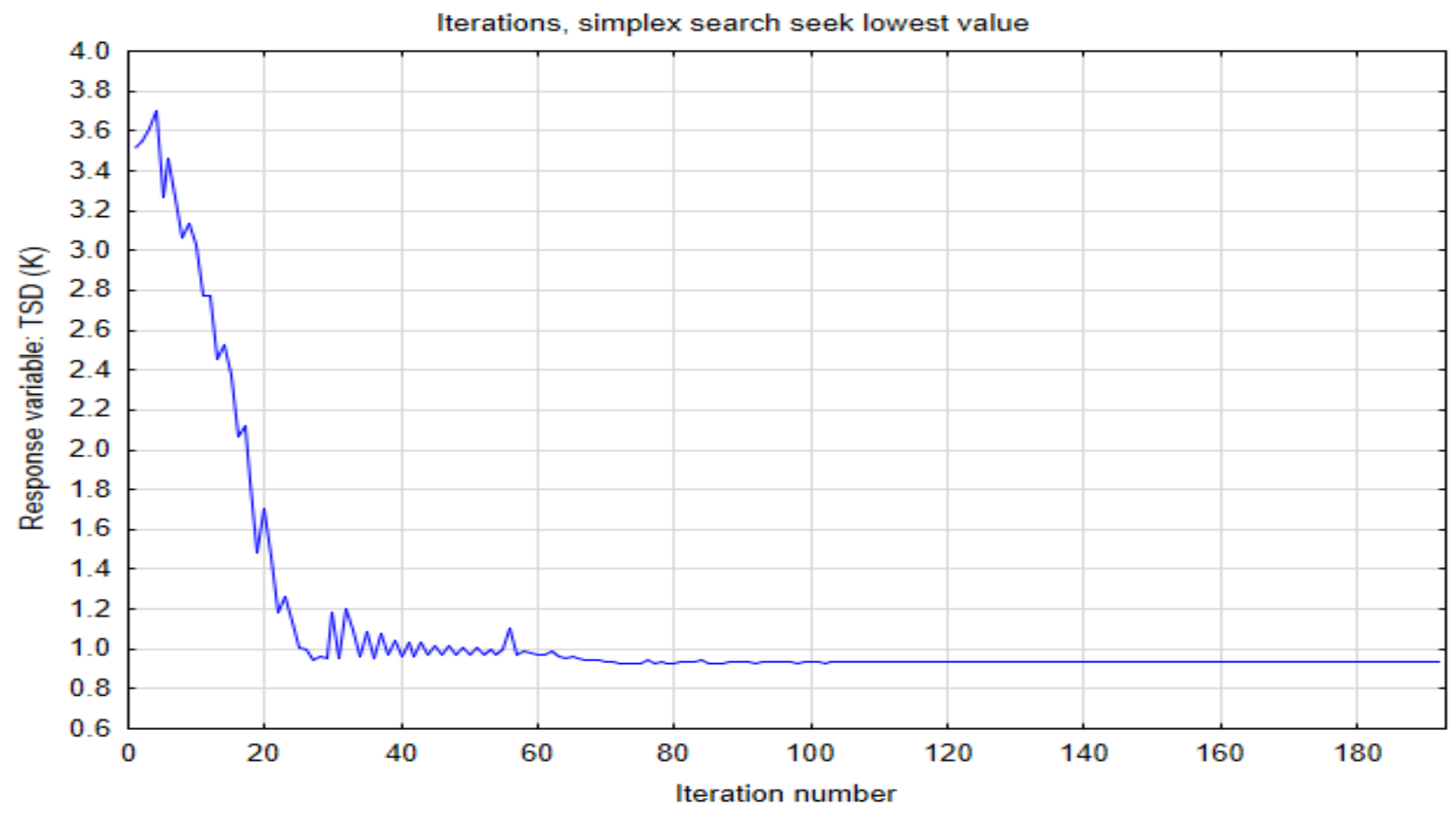

(c.)

Fig. 8 Optimization results for determination of minimum value of V, TD and TSD

\subsection{3-D surface plots and Simulation distribution for robustness validation}

3-D graphs are plotted between the response variable and the most influencing design variables determined by global sensitivity analysis. 3-D surface plots and sequential plots are used to study the variations of response variable due to interactions between the two or more-design variable. The nature or trend of variations in response variable is studied w.r.t variations in design variables. Fig. 9 shows the 3D surface plots of the V, TD and TSD w.r.t $\mathrm{X}_{4}$ and v design variables. 3-D sequential plots (Fig. 10), shows the plot of design variable and response variables, which describes the variation of all variables over whole range of run. 


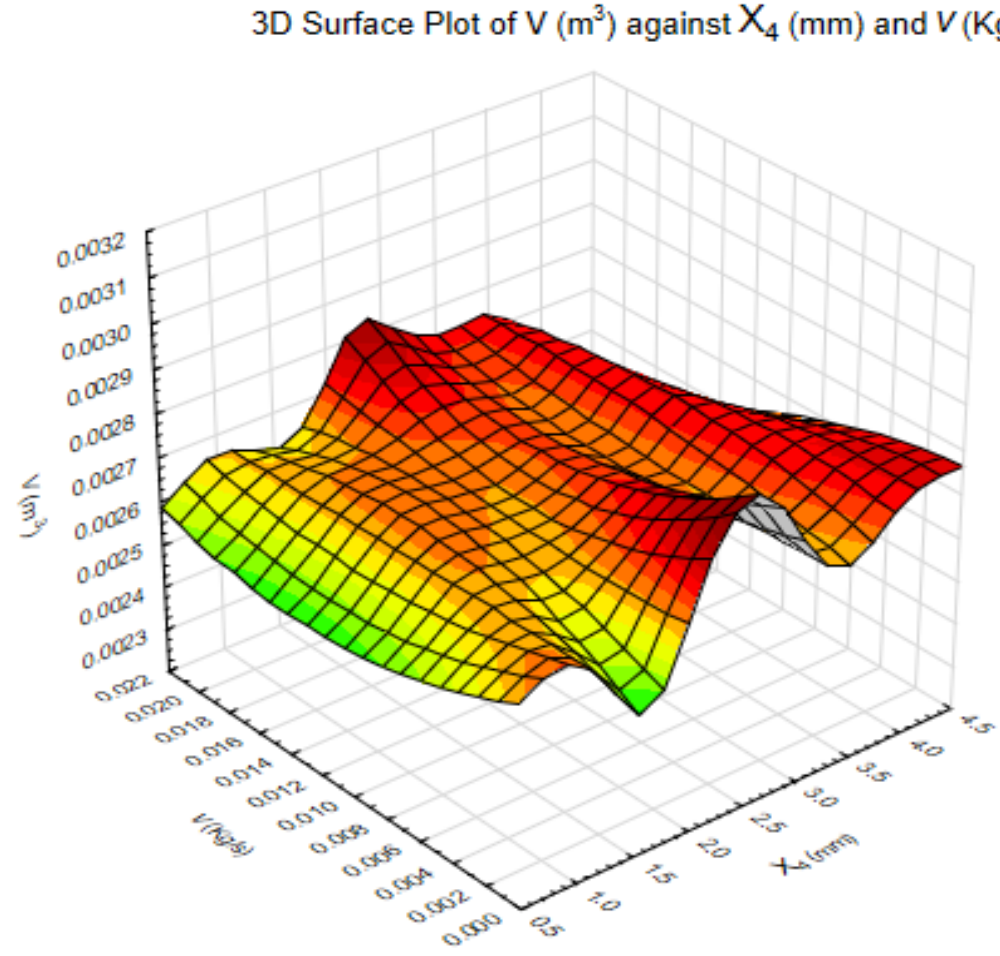

(a.)

396 

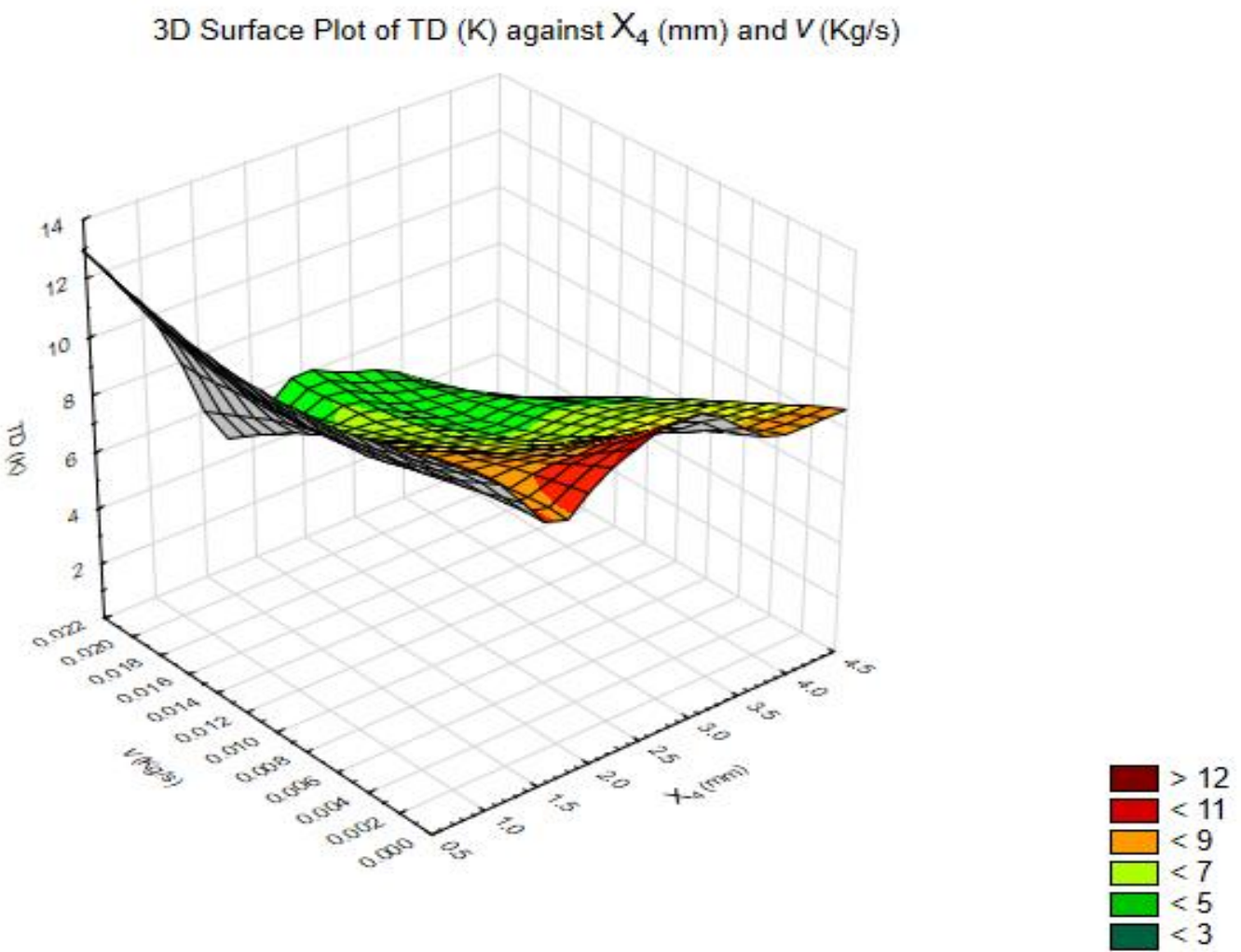

(b.)

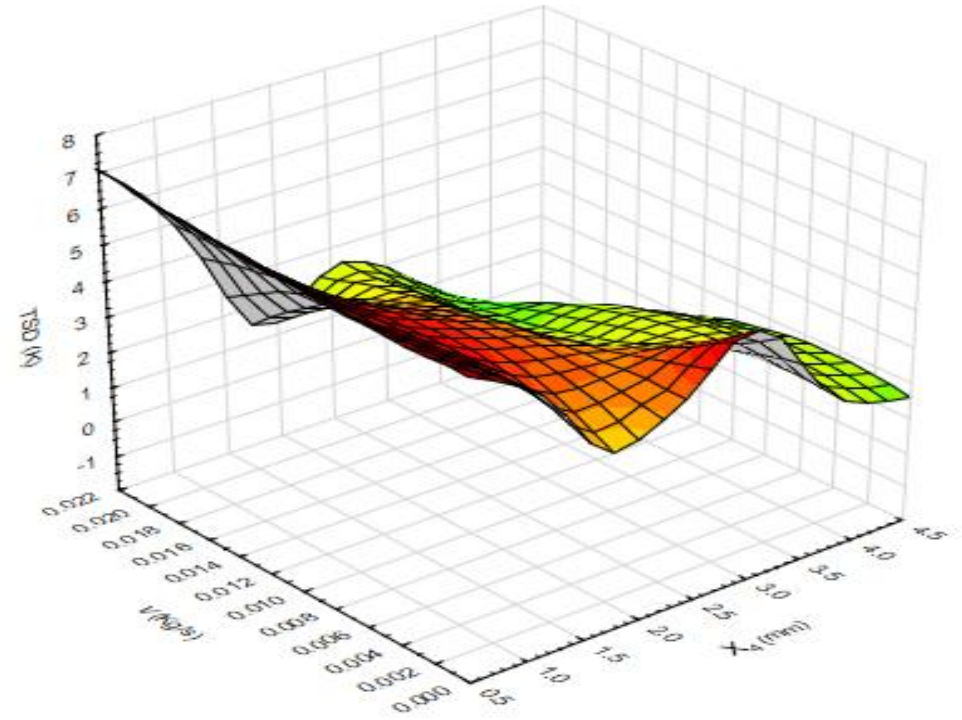

(c.) 
3D Sequential Graph for X1, X2, X3, X4, v, TD and TSD.

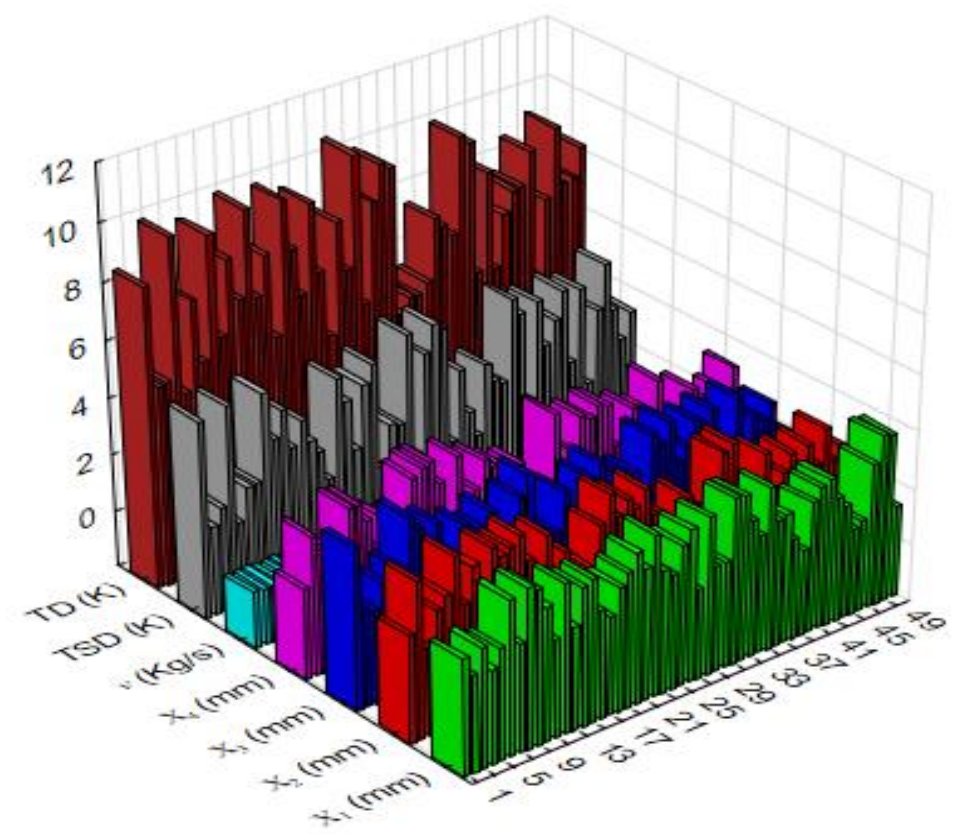

(a.)

408

3D Sequential Graph for $\mathrm{X}_{1}, \mathrm{X}_{2}, \mathrm{X}_{3}, \mathrm{X}_{4}, \mathrm{v}$ and $\mathrm{V}$.

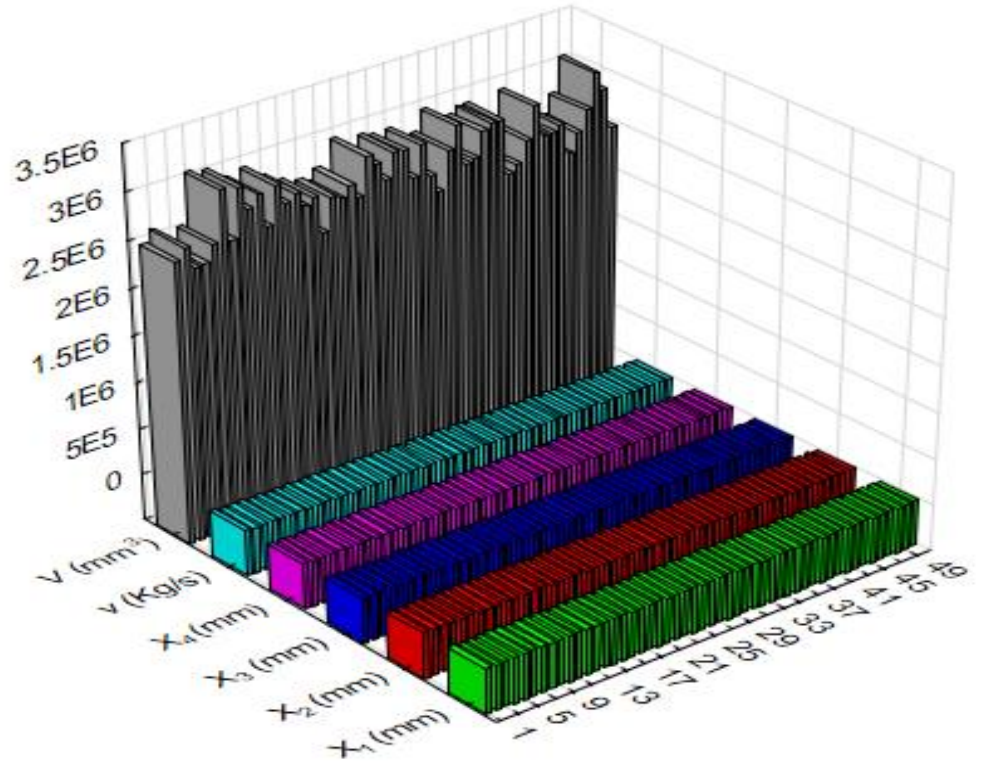

(b.)

411 Fig. 10 3D sequential plot showing variation of all variables over whole range of run 
412 Profiling of the ANS model is done to understand the desirability of response variables (V, TD and TSD) for different levels of individual input variables in their individual specified range.

414 Level of input variables which best fit with the desirability of the response variable is selected 415 as the set of conditions for design. Profiling of predicted values for individual response 416 variables (V, TD and TSD) are shown in Fig. 11. In Fig. 11 (a.) for response variable V it is 417 observed that $\mathrm{v}(\mathrm{Kg} / \mathrm{s})$ design variable is constant over range of $\mathrm{V}$, while other variables are 418 having linear variations and distribution is not reflecting any sudden changes. As shown in Fig. 41911 (b.), the response variable TD is also having normal distribution. The mean value of 420 response variable $\mathrm{TD}$ is in range $4 \mathrm{~K}$ to $7.3099 \mathrm{~K}$. Fig. 11 (c.) shows the skewness in 421 distribution of TSD for region above $3.217 \mathrm{~K}$.
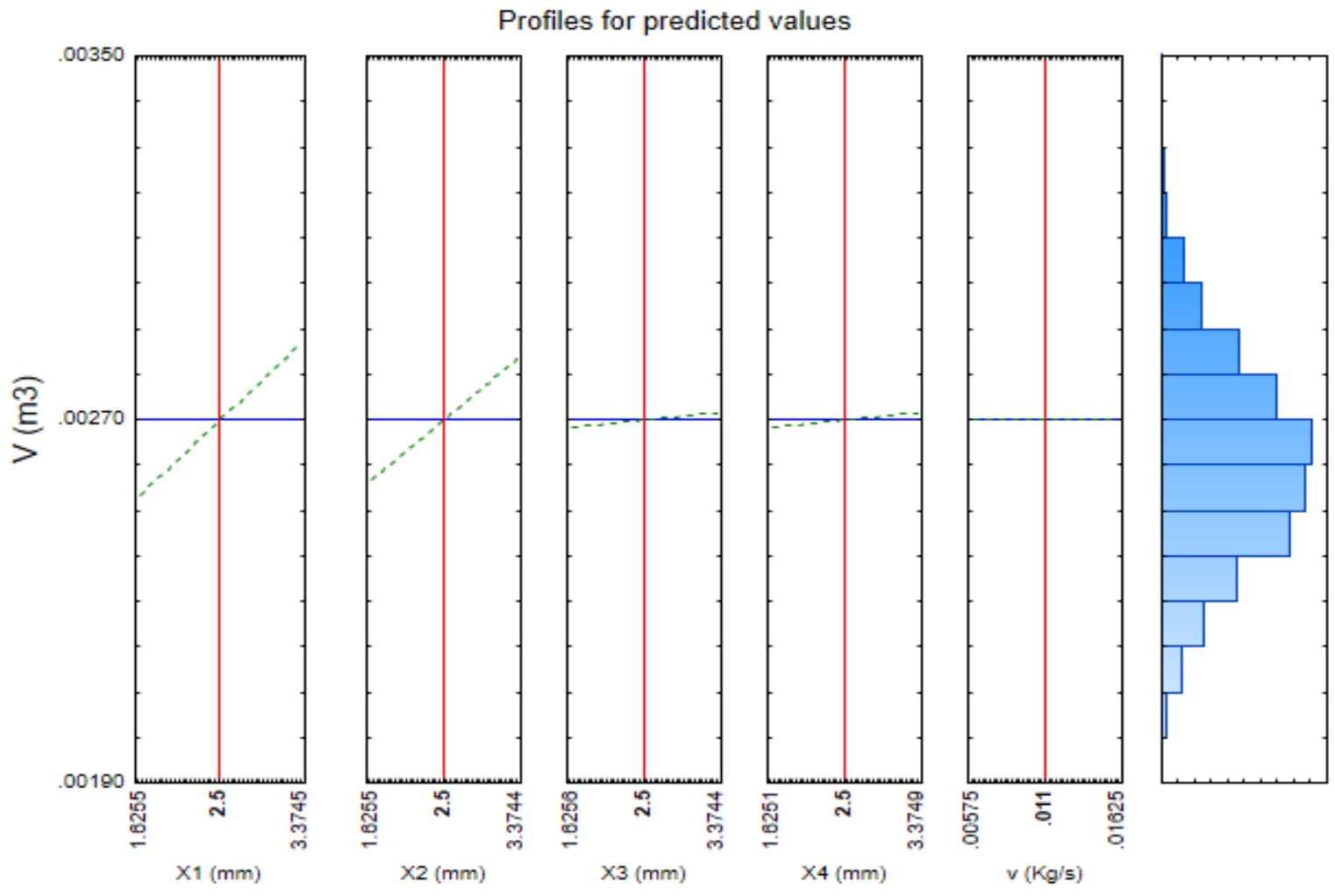


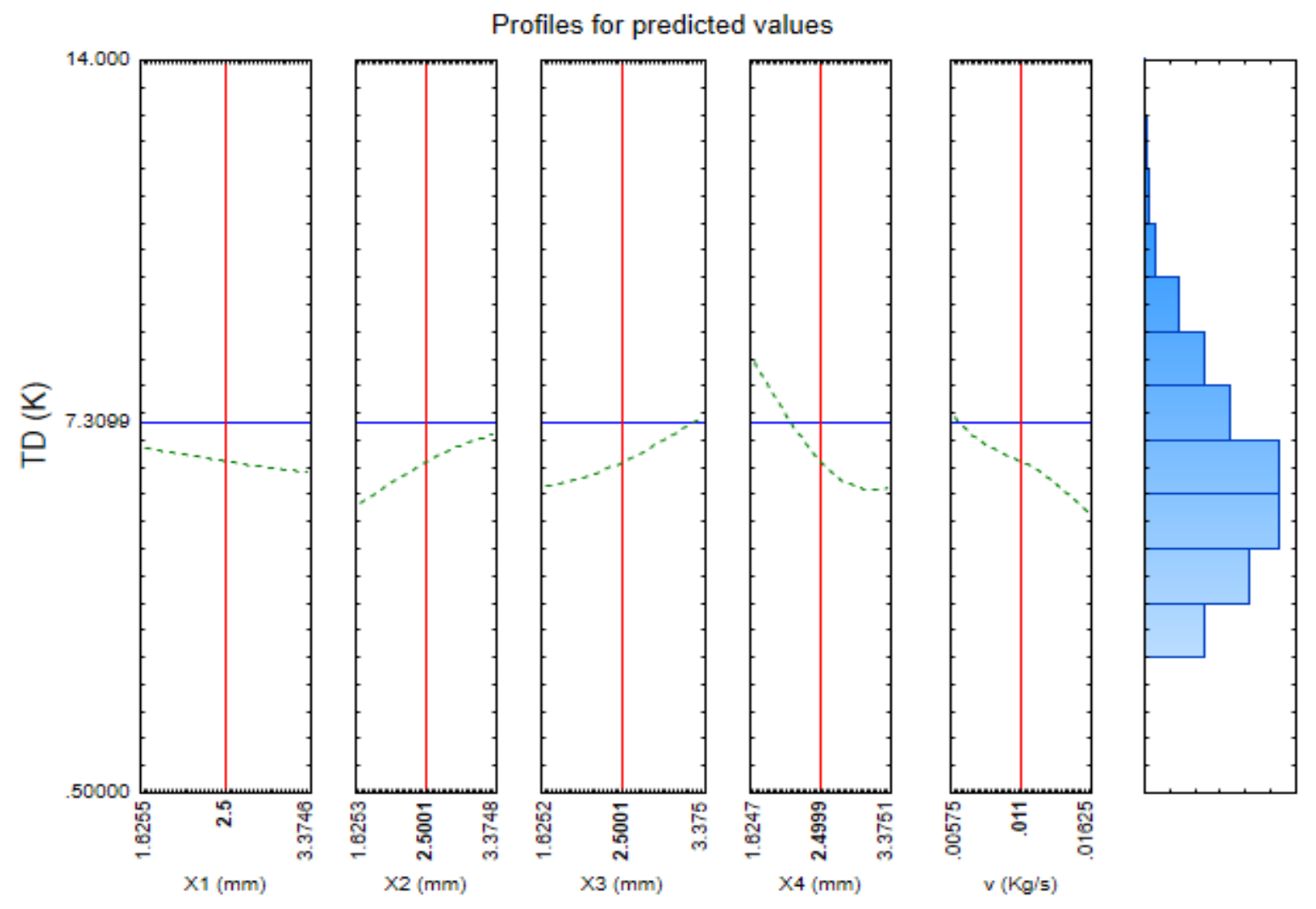

(b.)
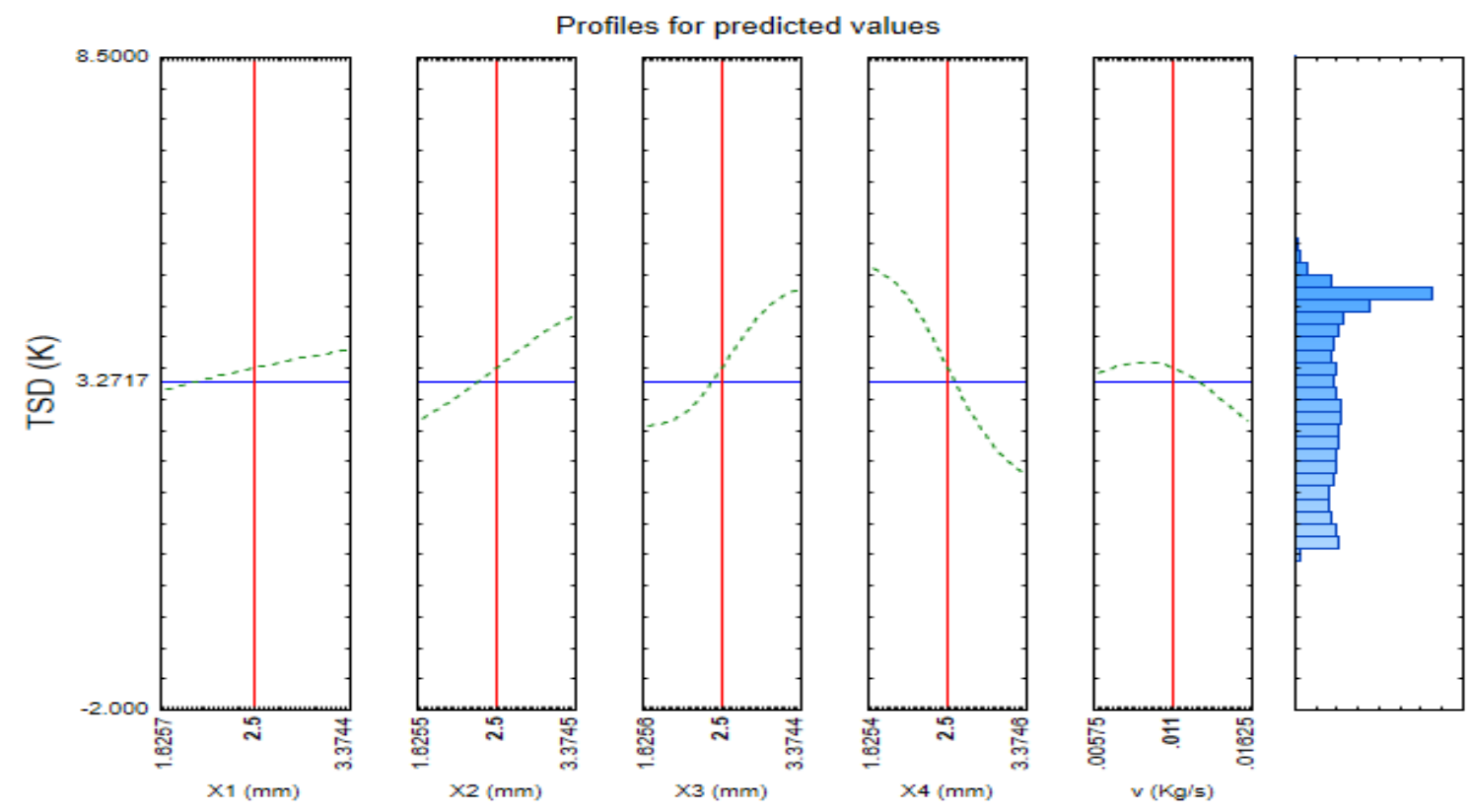

(c.)

Fig. 11 Profiling normal distribution of individual response variables on different levels 431 of input variables. 


\section{Conclusions}

433 In the current study, the research problem on optimization of design variables of battery module to minimize response variables (Maximum temperature differences, standard deviation of temperature over region of battery pack module and volume of battery pack) for air-cooling thermal management of battery module is undertaken. To solve this problem, a comprehensive FEM based ANS approach is proposed. The methodology is applied on the battery module comprising of eight prismatic cells. The optimized air-cooled battery pack module have better thermal performance in normal working conditions of EVs compared to initial designed scheme. The main findings from the analysis and optimization performed are as follows:

(1) The volume of the battery pack module decreases from $0.003279 \mathrm{~m}^{3}$ to $0.002321 \mathrm{~m}^{3}$ by $29.21 \%$ which addresses the space consumption in EVs and favors economical factors. The maximum temperature differences of the eight cells decreases from $6.81 \mathrm{~K}$ to 4.38 $\mathrm{K}$ by $35.66 \%$ and the temperature standard deviation reduces from $4.38 \mathrm{~K}$ to $0.93 \mathrm{~K}$ by $78.69 \%$

(2) The optimized air-cooled battery pack module has lesser volume consumption. This implies, it exhibits lower maximum temperature differences in battery module and the uniformity in temperature distribution over battery module is attained.

The present work provides an empirical and feasible model for design of battery thermal management system. This analysis can be scaled-up to battery packs comprising of 100 or more cells as in case of energy storage systems and commercial EVs.

\section{Acknowledgement}

Authors like to acknowledge Grant DMETKF2018019 by State Key Lab of Digital Manufacturing 
[1] Masayoshi, W. A. D. A. (2009). Research and development of electric vehicles for clean transportation. Journal of Environmental Sciences, 21(6), 745-749.

[2] Skerlos, S. J., \& Winebrake, J. J. (2010). Targeting plug-in hybrid electric vehicle policies to increase social benefits. Energy Policy, 38(2), 705-708.

[3] Avadikyan, A., \& Llerena, P. (2010). A real options reasoning approach to hybrid vehicle investments. Technological Forecasting and Social Change, 77(4), 649-661.

[4] Peterson, S. B., Whitacre, J. F., \& Apt, J. (2010). The economics of using plug-in hybrid electric vehicle battery packs for grid storage. Journal of Power Sources, 195(8), 2377-2384.

[5] Kempton, W., \& Letendre, S. E. (1997). Electric vehicles as a new power source for electric utilities. Transportation research. Part D, Transport and environment, 2(3), 157-175.

[6] T. R. Hawkins et al., "Comparative Environmental Life Cycle Assessment of Conventional and Electric Vehicles," J. Ind. Ecol. 17, 53 (2013).

[7] Woo, J., Choi, H., \& Ahn, J. (2017). Well-to-wheel analysis of greenhouse gas emissions for electric vehicles based on electricity generation mix: A global perspective. Transportation Research Part D: Transport and Environment, 51, 340-350.

[8] Lowe, M., Tokuoka, S., Trigg, T., \& Gereffi, G. (2010). Lithium-ion batteries for electric vehicles. The US Value Chain, Contributing CGGC researcher: Ansam Abayechi.

[9] Du, J. and Ouyang, M., 2013, November. Review of electric vehicle technologies progress and development prospect in China. In Electric Vehicle Symposium and Exhibition (EVS27), 2013 World (pp. 1-8). IEEE.

[10] Wen X, Xiao C. Electric vehicle key technology research in China. In Electrical Machines and Power Electronics and 2011 Electromotion Joint Conference (ACEMP), 2011 International Aegean Conference on 2011 Sep 8 (pp. 308-314). IEEE.

[11] Chen, X., Shen, W., Vo, T. T., Cao, Z., \& Kapoor, A. (2012, December). An overview of lithiumion batteries for electric vehicles. In IPEC, 2012 Conference on Power \& Energy (pp. 230-235). IEEE.

[12] Iclodean, C., Varga, B., Burnete, N., Cimerdean, D., \& Jurchiş, B. (2017, October). Comparison of Different Battery Types for Electric Vehicles. In IOP Conference Series: Materials Science and Engineering (Vol. 252, No. 1, p. 012058). IOP Publishing.

[13] Broussely, M., Planchat, J. P., Rigobert, G., Virey, D., \& Sarre, G. (1997). Lithium-ion batteries for electric vehicles: performances of 100 Ah cells. Journal of power sources, 68(1), 8-12.

[14] Lindgren, Juuso \& Lund, P. (2016). Effect of extreme temperatures on battery charging and performance of electric vehicles. Journal of Power Sources. 328. 37-45. 10.1016/j.jpowsour.2016.07.038.

[15] Leng, F., Tan, C. M., \& Pecht, M. (2015). Effect of temperature on the aging rate of Li ion battery operating above room temperature. Scientific reports, 5, 12967.

[16] Aris, A. M., \& Shabani, B. (2017). An Experimental Study of a Lithium Ion Cell Operation at Low Temperature Conditions. Energy Procedia, 110, 128-135.

[17] von Lüders, Christian, et al. "Lithium plating in lithium-ion batteries investigated by voltage relaxation and in situ neutron diffraction." Journal of Power Sources 342 (2017): 17-23.

[18] Park, C., \& Jaura, A. K. (2003). Dynamic thermal model of li-ion battery for predictive behavior in hybrid and fuel cell vehicles (No. 2003-01-2286). SAE Technical Paper.

[19] Bhatia, P. C. (2013). Thermal analysis of lithium-ion battery packs and thermal management solutions (Doctoral dissertation, The Ohio State University).

[20] Xia, G., Cao, L., \& Bi, G. (2017). A review on battery thermal management in electric vehicle application. Journal of Power Sources, 367, 90-105.

[21] De Vita, Armando, et al. "Transient thermal analysis of a lithium-ion battery pack comparing different cooling solutions for automotive applications." Applied Energy 206 (2017): 101-112. 
[22] Wang, Tao, et al. "Thermal investigation of lithium-ion battery module with different cell arrangement structures and forced air-cooling strategies." Applied energy 134 (2014): 229238.

[23] Huber, C. (2017). Phase Change Material in Battery Thermal Management Applications (Doctoral dissertation, Technische Universität München).

[24] Jaguemont, Joris, et al. "Phase-change materials (PCM) for automotive applications: a review." Applied Thermal Engineering (2017).

[25] Liu, Huaqiang, et al. "Thermal issues about Li-ion batteries and recent progress in battery thermal management systems: A review." Energy Conversion and Management 150 (2017): 304-330.

[26] Park H. A design of air flow configuration for cooling lithium ion battery in hybrid electric vehicles[J]. Journal of Power Sources, 2013, 239:30-36.

[27] Xun J, Liu R, Jiao K. Numerical and analytical modeling of lithium ion battery thermal behaviors with different cooling designs[J]. Journal of Power Sources, 2013, 233:47-61.

[28] Yang N, Zhang X, Li G, et al. Assessment of the forced air-cooling performance for cylindrical lithium-ion battery packs: A comparative analysis between aligned and staggered cell arrangements[J]. Applied Thermal Engineering, 2015, 80:55-65.

[29] Wang T, Tseng K J, Zhao J. Development of efficient air-cooling strategies for lithium-ion battery module based on empirical heat source model[J]. Applied Thermal Engineering, 2015, 90:521-529.

[30] Li W, Xiao M, Peng X, Garg A, Gao L. A surrogate thermal modeling and parametric optimization of battery pack with air cooling for EVs. Applied Thermal Engineering. 2019 Jan 25;147:90-100.

[31] Liao X, Ma C, Peng X, Garg A, Bao N. Temperature Distribution Optimization of an Air-Cooling Lithium-Ion Battery Pack in Electric Vehicles Based on the Response Surface Method. ASME. J.Electrochem. En. Conv. Stor.. 2019;16(4):041002-041002-8.

[32] Liu Yun, Sivasriprasanna Maddila, Liang Gao, Xiongbin Peng, Xiaodong Niu, Akhil Garg, Christina May May Chin, "An integrated framework for minimization of inter lithium?ion cell temperature differences and the total volume of the cell of battery pack for electric vehicles", Energy Storage. 2019; 1:e41.

[33] Zhao J, Rao Z, Li Y. Thermal performance of mini-channel liquid cooled cylinder based battery thermal management for cylindrical lithium-ion power battery[J]. Energy Conversion \& Management, 2015, 103:157-165.

[34] Huo Y, Rao Z, Liu X, et al. Investigation of power battery thermal management by using minichannel cold plate[J]. Energy Conversion \& Management, 2015, 89:387-395.

[35] Hwang, H. Y., Chen, Y. S., \& Chen, J. S. (2015). Optimizing the heat dissipation of an electric vehicle battery pack. Advances in Mechanical Engineering, 7(1), 204131.

[36] Shui L, Chen F, Garg A, et al. Design optimization of battery pack enclosure for electric vehicle[J]. Structural \& Multidisciplinary Optimization, 2018(4):1-17.

[37] Fan L, Khodadadi J M, Pesaran A A. A parametric study on thermal management of an aircooled lithium-ion battery module for plug-in hybrid electric vehicles[J]. Journal of Power Sources, 2013, 238: 301-312.

[38] Ling Z, Wang F, Fang X, et al. A hybrid thermal management system for lithium ion batteries combining phase change materials with forced-air cooling[J]. Applied energy, 2015, 148: 403409.

[39] Chaturvedi, D. K. (2008). Soft computing: techniques and its applications in electrical engineering (Vol. 103). Springer. 